\title{
A curved multi-component aerosol hygroscopicity model framework: Part 1 - Inorganic compounds
}

\author{
D. O. Topping, G. B. McFiggans, and H. Coe \\ School of Earth, Atmospheric and Environmental Sciences, The University of Manchester, The Sackville street building, \\ Sackville street, Manchester, M60 1QD, UK
}

Received: 17 November 2004 - Published in Atmos. Chem. Phys. Discuss.: 23 December 2004

Revised: 10 March 2005 - Accepted: 17 March 2005 - Published: 26 May 2005

\begin{abstract}
A thermodynamic modelling framework to predict the equilibrium behaviour of mixed inorganic salt aerosols is developed, and then coupled with a technique for finding a solution to the Kohler equation in order to create a diameter dependent hygroscopic aerosol model (Aerosol Diameter Dependent Equilibrium Model - ADDEM). The model described here provides a robust and accurate inorganic basis using a mole fraction based activity coefficient model and adjusted energies of formation for treating solid precipitation. The model framework can accommodate organic components, though this added complexity is considered in a companion paper, this paper describes the development of the modelling architecture to be used and predictions of an inorganic model alone. The modelling framework has been developed to flexibly use a combination of mixing rules and other potentially more accurate techniques where available to calculate the water content. Comparisons with other stateof-the-art general equilibrium models and experimental data are presented and show excellent agreement. The Kelvin effect can be considered in this scheme using a variety of surface tension models. Comparison of predicted diameter dependent phenomena, such as the increased relative humidity for onset of deliquescence with decreasing diameter, with another diameter dependent model is very good despite the different approach used. The model is subject to various sensitivities. For the inorganic systems studied here, the model is sensitive to choice of surface tension scheme used, which decreases for larger aerosol. Large sensitivities are found for the value of dry density used. It is thus likely that the history of the aerosol studied in a hygroscopic tandem differential mobility analyser (HTDMA), specifically the nature of the drying process that will influence the final crystalline form, will create systematic uncertainties upon comparisons with theoretical predictions. However, the magnitudes of all of
\end{abstract}

Correspondence to: D. O. Topping

(david.topping@ postgrad.manchester.ac.uk) the above sensitivities are potentially less than those introduced when using a semi ideal growth factor analogue for certain conditions.

\section{Introduction}

The interaction between aerosols and water vapour plays a large role in determining their effect on the environment. The chemical and physical characteristics of aerosols are diverse and attempting to encompass such variability within a hygroscopic model is complex. An aerosol may exist in a solid or liquid state or a combination of the two over a wide range of ambient conditions both in the sub and super saturated humid environment (Corrigan and Novakov, 1999; Pitchford and Mcmurry, 1994; Shulman et al., 1996; Swietlicki et al., 1999). Thus, where possible, the ability to couple the chemical and physical characteristics to the equilibrium phase of the aerosol is the ultimate aim of any hygroscopic modelling approach. Indeed, Martin et al. (2004) found that direct radiative forcing estimates were particularly sensitive to the predicted physical state of the aerosol.

Chemical components include sulphates, nitrates, ammonium, sea salt, hydrogen ions, crustal components and organic material (Seinfeld and Pandis, 1998). In the past, only the inorganic fraction has been assumed to play a role in the interaction between aerosols and water vapour. As such, this fraction has been studied and modelled extensively and our understanding of its behaviour is relatively robust, despite various shortcomings of the previous modelling approaches, which are addressed in this paper.

The accuracy with which one treats the hygroscopic properties of aerosols can be determined by the framework of the modelling approach, which in turn is often developed with varying levels of flexibility in mind. One can categorise such frameworks using the assumptions associated with each. Ultimately these range from empirical parameterisations to

(C) 2005 Author(s). This work is licensed under a Creative Commons License. 


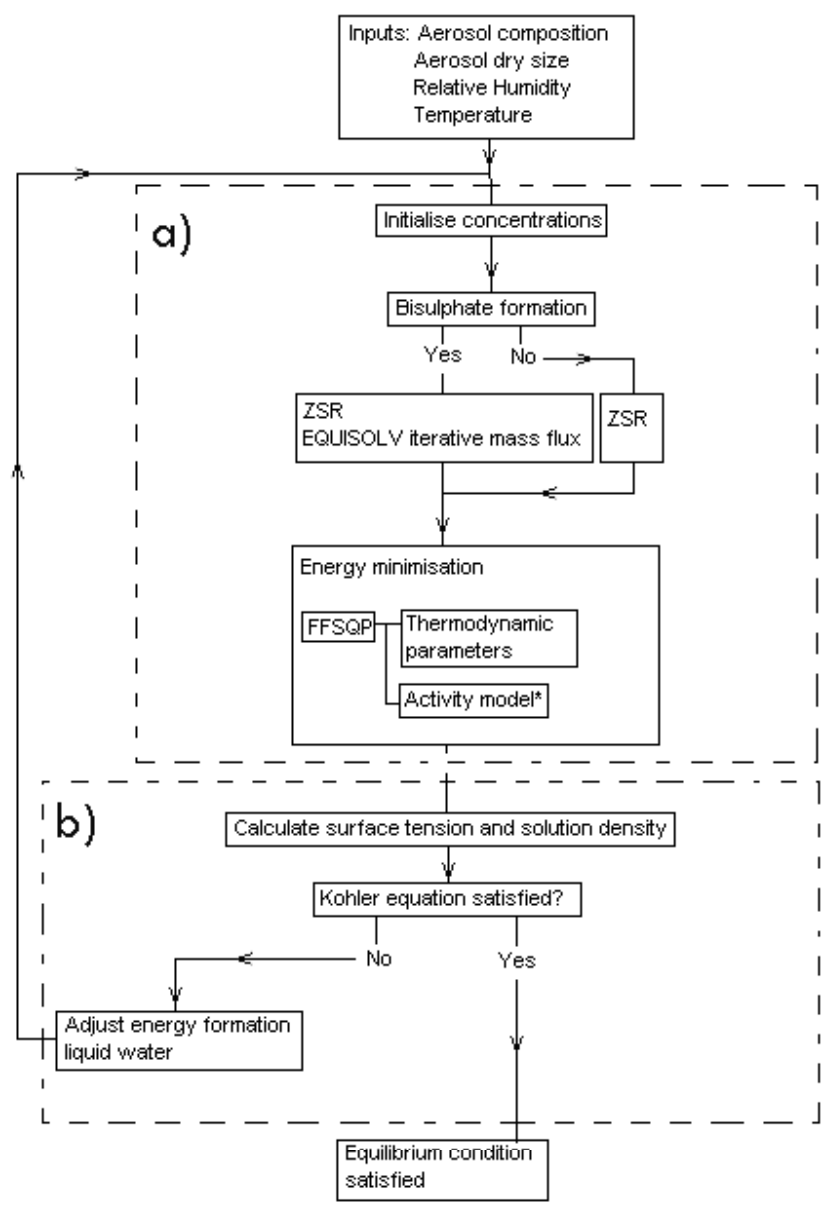

Fig. 1. Diameter dependent inorganic equilibrium model schematic. (a) The general equilibrium model framework without Kelvin effect, (b) the additional iterative scheme for treating the Kelvin effect.

semi empirical thermodynamic models. Whilst easier to implement, the former are potentially less accurate and are not as applicable to as wide a range of atmospheric situations. Ideally an explicit treatment of the underlying thermodynamics is required.

Numerous inorganic thermodynamic models have been developed. These include EQUIL (Bassett and Seinfeld, 1983), KEQUIL (Bassett and Seinfeld, 1984), MARS (Saxena et al., 1986), SEQUILIB (Pilinis and Seinfeld, 1987), SCAPE and SCAPE 2 (Kim and Seinfeld, 1995; Kim et al., 1993a, b; Meng et al., 1995), MARS-A (Binkowski and Shankar, 1995),EQUISOLV and EQUISOLV II (Jacobson, 1999b; Jacobson et al., 1996), AIM and AIM 2 (Clegg et al., 1998a, b; Wexler and Seinfeld, 1990, 1991), ISSORROPIA (Nenes et al., 1998, 1999), GFEMN (Ansari and Pandis, 1999) and EQSAM (Metzger et al., 2002a, b). Comparative reviews are given in the literature (Saxena et al., 1986; Zhang et al., 2000). These models treat the inorganic fraction with varying levels of complexity, often dictated by the nu- merical technique chosen and the activity coefficient model employed. One can classify the different techniques used to determine the equilibrium composition and phase state of the aerosols into two main categories. The first utilises equilibrium constants housed within varying levels of iteration. Whilst relatively easy to implement, the use of such schemes often results in the sole use of mixing rules to calculate the water content. Although proven to be relatively successful for inorganic systems, it would be beneficial to devise a framework in which potentially more accurate techniques for calculating the water content can be employed given that errors associated with organics are likely to be significant,. In addition, as noted by Ansari and Pandis (1999), conditions suggesting multistage behaviour and quantifying the degree of deliquescence depression are not known a priori. As such, modifying an equation-based algorithm to predict multistage behaviour and deliquescence depression is difficult (Ansari and Pandis, 1999). A more fundamental approach centres on a search for the global Gibbs free energy minimum using either predetermined reaction paths or allowing the components to be freely variable within set charge and mass constraints. Whilst much harder to implement, this approach allows the use of both mixing rules and potentially more accurate techniques for calculating the water content. A further benefit is that these techniques allow a treatment of multistage behaviour of volatile compounds. The model described in this paper relies on such a technique.

Another shortcoming of the majority of inorganic models available is the lack of a coupled consideration of aerosol particle curvature and composition, the Kelvin effect. Curvature influences the partitioning of volatile compounds between the aerosol and gas phase. Whilst negligible for aerosols larger than $100 \mathrm{~nm}$ dry diameter, not treating the Kelvin effect restricts the range of applicability of the model both with respect to ambient conditions and the aerosol population being studied. However, introduction of the Kelvin effect is difficult; of the above models, only KEQUIL attempts to treat it by utilising the Gibbs-Thomson relation for each appropriate component. Whilst this is an entirely feasible approach, there are complicating issues, not least the requirement for complex derivatives when using thermodynamic models for the surface tension (in KEQUIL the surface tension is assumed to be that of pure water which introduces inconsistencies). Ming and Russell (2002) introduce the Kelvin effect into their thermodynamic model by deriving an expression for the change in Gibbs free energy from an initially dry to a wet aerosol. Here the surface tension is calculated using the formulation of Suarez et al. (1989) and the authors assume that the surface concentrations are proportional to the bulk by using a proportionality constant derived from measurements of binary systems. The model presented here combines the framework developed around a direct minimisation of the Gibbs free energy and the equilibration of water governed by the simple Kohler equation in order to find a solution pertaining to the new definition of equilibrium. In this manner, 
one can utilise a wide variety of surface tension models, the most complicated of which may treat the surface/bulk concentration relations explicitly.

In this paper, a general equilibrium model is described before a method for treating the Kelvin effect is introduced. In this way a diameter dependent equilibrium model is developed (ADDEM - Aerosol Diameter Dependent Equilibrium Model). Comparisons with other techniques that are available are made during these developments, finishing with a variety of sensitivity studies. This paper deals with the essential components for calculating the equilibrium state and composition of a solely inorganic aerosol. In this manner, a robust basis on which to include organics is described in detail. An approach to extending this model to include mixed inorganic/organic aerosols is discussed in the companion paper (Topping et al., 2004).

\section{General inorganic equilibrium model}

In this section, the theoretical and numerical requirements for a general equilibrium model are described. Figure 1 shows a basic model schematic for the current model. The following section describes the portion outlined by the dashed box labelled 'a)'.

\subsection{Thermodynamics}

One needs to determine the chemical equilibrium of an aerosol for a given composition and ambient conditions. The condition for chemical equilibrium at constant temperature $(T)$ and pressure $(P)$ is that the total Gibbs free energy of the system is at the global minimum (Denbigh, 1981). The Gibbs free energy $(G)$ is a function of temperature, pressure and the number of moles of each component being considered:

$G=\sum_{i} n_{i} \mu_{i}$

Where $\mu_{i}$ is the chemical potential of component $i$, and $n_{i}$ the corresponding number of moles. An aerosol may consist of an aqueous phase at high relative humidity $(R H)$, one or more solid phases at low $R H$ and both aqueous and solid phases at intermediate $R H$ (Wexler and Seinfeld, 1991). Thus the system treated here includes water in both the liquid and gas phase and inorganic components in the gas, liquid and solid phase. The definitions of chemical potentials for ionic components, gases, water and solids are, respectively:

$$
\begin{aligned}
\mu_{i} & =\mu_{i}^{o}(T)+R T \ln \left(\gamma_{i} m_{i}\right) \\
\mu_{i} & =\mu_{i}^{o}(T)+R T \ln \left(p_{i}\right) \\
\mu_{i} & =\mu_{i}^{o}(T)+R T \ln \left(a_{w}\right) \\
\mu_{i} & =\mu_{i}^{o}(T)
\end{aligned}
$$

Where $\mu_{i}^{o}(T)$ is the standard state chemical potential $(\mathrm{kJ}$ $\left.\mathrm{mol}^{-1}\right), R$ is the universal gas constant $(0.0083145 \mathrm{~kJ}$ $\left.\mathrm{mol}^{-1}\right), T$ is the temperature $(\mathrm{K}), \gamma_{i}$ the activity coefficient, $m_{i}$ the molality ( $\mathrm{mol} \mathrm{kg}^{-1}$ water) and $p_{i}$ the partial pressure (atm) of component $i$. For gases at atmospheric pressure, ideality is assumed. The temperature dependence of the standard state chemical potential is calculated from:

$\mu_{i}^{o}(T)=T\left[\frac{\Delta G_{f}^{o}}{T_{o}}+\Delta H\left(\frac{1}{T}-\frac{1}{T_{o}}\right)+c_{p}\left(\ln \frac{T_{o}}{T}-\frac{T_{o}}{T}+1\right)\right]$

where $\Delta G_{f}^{o}$ is the free energy of formation $\left(\mathrm{kJ} \mathrm{mol}^{-1}\right), \Delta H$ is the standard heat of formation $\left(\mathrm{kJ} \mathrm{mol}^{-1}\right)$, and $c_{p}$ the heat capacity $\left(\mathrm{kJ} \mathrm{mol}^{-1}\right)$, all at $\mathrm{T}_{o}$, a reference temperature (298.15 K). Such data is compiled in Table 1. Currently the model treats the following components in the gas, solid and aqueous phase:

Gas: $\mathrm{HNO}_{3}, \mathrm{HCl}, \mathrm{NH}_{3}, \mathrm{H}_{2} \mathrm{O}$

Solid: $\quad \mathrm{NaCl}, \quad \mathrm{Na}_{2} \mathrm{SO}_{4}, \quad \mathrm{NaHSO}_{4}, \quad \mathrm{NaNO}_{3}$, $\left(\mathrm{NH}_{4}\right)_{2} \mathrm{SO}_{4} \mathrm{NH}_{4} \mathrm{HSO}_{4}, \quad \mathrm{NH}_{4} \mathrm{NO}_{3}, \quad \mathrm{NH}_{4} \mathrm{Cl}$, $\mathrm{Na}_{2} \mathrm{SO}_{4} \cdot 10 \mathrm{H}_{2} \mathrm{O}, \quad \mathrm{NaHSO}_{4} \cdot \mathrm{H}_{2} \mathrm{O}, \quad \mathrm{NaNO}_{3} \cdot \mathrm{Na}_{2} \mathrm{SO}_{4} \cdot \mathrm{H}_{2} \mathrm{O}$, $(\mathrm{Na})_{2} \mathrm{SO}_{4} \cdot\left(\mathrm{NH}_{4}\right)_{2} \mathrm{SO}_{4} \cdot \mathrm{H}_{2} \mathrm{O}, \quad \mathrm{NH}_{4} \mathrm{NO}_{3} \cdot \mathrm{NH}_{4} \mathrm{HSO}_{4}$, $2 \mathrm{NH}_{4} \mathrm{NO}_{3} \cdot\left(\mathrm{NH}_{4}\right)_{2} \mathrm{SO}_{4}$ and $3 \mathrm{NH}_{4} \mathrm{NO}_{3} \cdot\left(\mathrm{NH}_{4}\right)_{2} \mathrm{SO}_{4}$

Aqueous:: $\mathrm{H}^{+}, \mathrm{Na}^{+}, \mathrm{NH}_{4}^{+}, \mathrm{SO}_{4}^{2-}, \mathrm{HSO}_{4}^{2-}, \mathrm{NO}_{3}^{-}, \mathrm{Cl}^{-}$

The components in italic are those that can be modelled at temperatures other than $298.15 \mathrm{~K}$ in accordance with the activity coefficient model described in the following text.

Given the form of $\mu_{i}$ in the Gibbs energy summation, this means that one needs to solve a non-linear problem. However, the system is also subject to charge and mass constraints. For example, in calculating the partitioning of sulphate between the aqueous and solid phase, the total sulphate concentration should be conserved whilst also maintaining a charge balance in solution. This is applicable to all components.

Thus, determining the global minimum of Eq. (1) requires that one solve a constrained non-linear problem. This requires the use of complex numerical algorithms that either rely on an exhaustive search (GFEMN) or use gradient information to converge on the solution much faster (AIM). Unconstrained optimisation algorithms are widely available (e.g. Press et al., 1992). However, constrained algorithms are more complex and less readily available. The model presented here currently uses the algorithm FFSQP (Fast Fortran Sequential Quadratic Programming) (Zhou et al., 1997) where the gradient of the Gibbs energy surface is calculated using the Gibbs-Duhem relationship:

$\frac{\partial G}{\partial n_{i}}=\mu_{i}$

In the presence of the $\mathrm{H}^{+}$and $\mathrm{SO}_{4}^{2-}$ ions, it is necessary to consider the bisulphate dissociation explicitly:

$\mathrm{HSO}_{4}^{-} \leftrightarrow \mathrm{H}^{+}+\mathrm{SO}_{4}^{2-}$

In treating the sulphuric acid-water system for example, the reaction $\mathrm{H}_{2} \mathrm{SO}_{4}(\mathrm{~g}) \leftrightarrow \mathrm{H}_{2} \mathrm{SO}_{4}(\mathrm{aq})$ is not considered as $\mathrm{H}_{2} \mathrm{SO}_{4(g)}$ can be assumed to completely dissociate to $\mathrm{HSO}_{4}^{-}$ 
Table 1. Thermodynamic parameters used in the model. \% Deviation values indicate the deviation between the adjusted energies of formation and those tabulated in the first column.

\begin{tabular}{|c|c|c|c|c|c|c|c|}
\hline Species & $\begin{array}{l}\Delta \mathrm{G}_{\mathrm{f}}^{\mathrm{o}} \\
\left(\mathrm{kJ} \mathrm{mol}^{-1}\right)\end{array}$ & $\begin{array}{l}\Delta \mathrm{H}_{\mathrm{f}}{ }^{\mathrm{o}} \\
\left(\mathrm{kJ} \mathrm{mol}^{-1}\right)\end{array}$ & $\begin{array}{l}\mathrm{C}_{\mathrm{p}}{ }^{\mathrm{O}} \\
\left(\mathrm{J} \mathrm{mol}^{-1}\right)\end{array}$ & 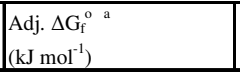 & $\begin{array}{l}\% \text { Deviation } \\
\text { (this study) }\end{array}$ & (Ansari and Pandis 1999) & DRH (\%) \\
\hline $\mathrm{NH}_{4} \mathrm{NO}_{3}(\mathrm{~s})$ & -183.87 & -365.56 & 139.3 & -184.4116215 & 0.295 & 0.37 & 62 \\
\hline$\left(\mathrm{NH}_{4}\right)_{2} \mathrm{SO}_{4}(\mathrm{~s})$ & -901.67 & -1180.85 & 187.49 & -902.9684592 & 0.144 & 0.16 & 80 \\
\hline $\mathrm{NH}_{4} \mathrm{HSO}_{4}(\mathrm{~s})$ & -823 & -1026.96 & 127.5 & -822.7440844 & 0.031 & 0.02 & 40 \\
\hline$\left(\mathrm{NH}_{4}\right)_{3} \mathrm{H}\left(\mathrm{SO}_{4}\right)_{2}(\mathrm{~s})$ & -1730 & -2207 & 315 & -1731.801894 & 0.104 & 0.18 & 69 \\
\hline $\mathrm{Na}_{2} \mathrm{SO}_{4}(\mathrm{~s})$ & -1270.16 & -1387.08 & 128.2 & -1268.1116 & 0.161 & 0.05 & 84 \\
\hline $\mathrm{NaHSO}_{4}(\mathrm{~s})$ & -992.8 & -1125.5 & 85 & -1005.081095 & 1.237 & 1.26 & 52 \\
\hline $\mathrm{NaCl}(\mathrm{s})$ & -384.14 & -411.15 & 50.5 & -384.0132158 & 0.033 & 0.09 & 75 \\
\hline $\mathrm{NaNO}_{3}(\mathrm{~s})$ & -367 & -461.75 & 92.88 & -367.0149944 & 0.004 & 0.03 & 74 \\
\hline $\mathrm{NH}_{4} \mathrm{Cl}(\mathrm{s})$ & -202.87 & -314.43 & 84.1 & -205.1639246 & 1.131 & 0.95 & 80 \\
\hline $\mathrm{NH}_{3}(\mathrm{~g})$ & -16.45 & -46.11 & 35.06 & \multirow{11}{*}{$-237.16619243942^{b}$} & \multirow{11}{*}{0.015} & & \\
\hline $\mathrm{HNO}_{3}(\mathrm{~g})$ & -74.72 & -135.06 & 53.35 & & & & \\
\hline $\mathrm{HCl}(\mathrm{g})$ & -95.3 & -92.31 & 29.13 & & & & \\
\hline $\mathrm{H}_{2} \mathrm{O}(\mathrm{g})$ & -228.57 & -241.82 & 33.58 & & & & \\
\hline $\mathrm{H}_{2} \mathrm{O}(\mathrm{l})$ & -237.13 & -285.83 & 75.29 & & & & \\
\hline $\mathrm{NH}_{4}^{+}(\mathrm{aq})$ & -79.31 & -132.51 & 79.9 & & & & \\
\hline $\mathrm{Na}^{+}(\mathrm{aq})$ & -261.91 & -240.12 & 46.4 & & & & \\
\hline $\mathrm{NO}_{3}^{-}(\mathrm{aq})$ & -111.25 & -207.36 & -86.6 & & & & \\
\hline $\mathrm{SO}_{4}{ }^{2-}(\mathrm{aq})$ & -744.53 & -909.27 & -293 & & & & \\
\hline $\mathrm{Cl}^{-}(\mathrm{aq})$ & -131.23 & -167.16 & -136.4 & & & & \\
\hline $\mathrm{HSO}_{4}{ }^{-}(\mathrm{aq})$ & -755.91 & -887.34 & -84 & & & & \\
\hline
\end{tabular}

in the atmosphere for all practical purposes (Seinfeld and Pandis, 1998). Rather than iterating around an equilibrium constant, the model presented here treats the dissociation given by Eq. (5) within the Gibbs energy minimisation. This tends to simplify matters somewhat as one simply adds another component and changes the mass/charge constraints accordingly.

\subsubsection{Solute activity coefficients}

Perhaps the most important and most complex variable to deal with is the activity of the aqueous components $\left(\gamma_{i}\right)$ given in Eq. (2). It is this aspect of the thermodynamic module that determines the range of applicability of the equilibrium model. There are various options available (see Pilinis, 1999), however the most accurate are semi-empirical thermodynamic models. In solution mixtures of strong electrolytes where association of ions is assumed not to occur, an ion-interaction rather than ion-pairing model is the appropriate choice (Clegg and Brimblecombe, 1988). Pitzer's molality based model (Pitzer, 1973, 1975; Pitzer and Mayorga, 1973; Pitzer and Silvester, 1976) had been the most powerful and widely used, yet the severe concentration limitations associated with it prevent its use for predictions in low $R H$ regions where aerosols may exist in states of very high aqueous concentrations. Many of these concentration limitations are overcome by using the Pitzer, Simonson and Clegg mole fraction based approach (PSC, Clegg and Pitzer, 1992; Clegg et al., 1992). On a mole fraction scale, the activity of component $i\left(a_{i}\right)$ is calculated by:

$a_{i}=f_{i} x_{i}$
Where $x_{i}$ is the mole fraction and $f_{i}$ the mole fraction activity coefficient of component $i$. The expressions for $f_{i}$ are complex and can be found in the literature (Clegg and Pitzer, 1992; Clegg et al., 1992). Such expressions rely upon the use of component mole fractions, binary and ternary interaction parameters. Currently interaction parameters are available for two systems. The first treats the components $\mathrm{H}^{+}+\mathrm{NH}_{4}^{+}$ $+\mathrm{Na}^{2+}+\mathrm{SO}_{4}^{2-}+\mathrm{NO}_{3}^{-}+\mathrm{Cl}^{-}+\mathrm{H}_{2} \mathrm{O}$ at $298.15 \mathrm{~K}$. Similarly the authors successfully applied the model to system $\mathrm{H}^{+}+$ $\mathrm{NH}_{4}^{+}+\mathrm{SO}_{4}^{2-}+\mathrm{NO}_{3}^{-}+\mathrm{H}_{2} \mathrm{O}$ over a range of tropospheric temperatures.

The mole fraction of component $i$ is given by

$x_{i}=\frac{n_{i}}{\sum_{j} n_{j}}$

where the summation is over all aqueous components. For use in this model, the activity must be calculated on a molality scale. Activity coefficients on a mole fraction scale are related to the molality-based coefficients by:

$f_{i}=\gamma_{i}\left(1+\left(M_{1} / 1000\right) \sum_{j} m_{j}\right)$

Where $M_{1}$ is the molar mass of the solvent $\left(M_{\text {water }}=18 \mathrm{gmol}^{-1}\right)$ and the summation is over the molality of all aqueous components. For systems in which water is the only solvent this reduces to:

$f_{i} x_{w a t e r}=\gamma_{i}$ 
Table 2. Deliquescence relative humidity (DRH) of mixed particles at $25^{\circ} \mathrm{C}$.

\begin{tabular}{|c|c|c|c|c|c|c|c|c|}
\hline \multirow[t]{2}{*}{ Components } & \multirow{2}{*}{$\begin{array}{l}\text { Measured DRH } \\
\left(25^{\circ} \mathrm{C}\right)\end{array}$} & \multicolumn{3}{|c|}{ Predicted DRH } & \multirow{2}{*}{\multicolumn{2}{|c|}{ AIM online }} & \multirow{2}{*}{\multicolumn{2}{|c|}{ ADDEM }} \\
\hline & & GFEMN & Sequilib & SCAPE2 & & & & \\
\hline $\mathrm{NaCl}-\mathrm{NaNO}_{3}$ & $68.0+/-0.4$ & 67.6 & 62.1 & $67.3^{\mathrm{a}}$ & 67.27 & & 67.1 & \\
\hline $\mathrm{NaCl}-\mathrm{Na}_{2} \mathrm{SO}_{4}$ & $74.2+/-0.3$ & 72.8 & 62.1 & $72.0^{\mathrm{a}}$ & 74.34 & & 73.5 & \\
\hline $\mathrm{Na}_{2} \mathrm{SO}_{4}-\left(\mathrm{NH}_{4}\right)_{2} \mathrm{SO}_{4}$ & $71.3+/-0.4$ & 70.2 & 80.1 & $67.5^{b}$ & 71.92 & $82.9^{c}$ & 69.9 & $82.9^{\mathrm{c}}$ \\
\hline $\mathrm{Na}_{2} \mathrm{SO}_{4}-\mathrm{NaNO}_{3}$ & $72.2+/-0.2$ & 72.2 & 62.1 & $72.8^{b}$ & 72.93 & $80.61^{\mathrm{d}}$ & 72.3 & $80.7^{\mathrm{d}}$ \\
\hline $\begin{array}{l}\text { All values are repro } \\
\text { AIM and ADDEM } \\
\text { AIM and ADDEM }\end{array}$ & $\begin{array}{l}\text { sults found using R } \\
\text { edictions also give }\end{array}$ & $\begin{array}{l}\text { andis (1999) } \\
\text { tervals of } 0.1^{\circ} \\
\text { ts upon inclu }\end{array}$ & $\begin{array}{l}\text { apart from A } \\
\% \\
\text { ision of hydra }\end{array}$ & $\begin{array}{l}\text { IM results } \\
\text { ated salts for }\end{array}$ & the last two & tems & & \\
\hline \multicolumn{9}{|c|}{${ }^{a}$ Bromley method for activity coefficients } \\
\hline \multicolumn{9}{|c|}{${ }^{\mathrm{b}}$ Pitzer method for activity coefficients } \\
\hline \multicolumn{9}{|c|}{${ }^{\mathrm{c}} \mathrm{DRH}$ found when including $\left(\mathrm{NH}_{4}\right)_{2} \mathrm{SO}_{4} \cdot \mathrm{Na}_{2} \mathrm{SO}_{4} \cdot 4 \mathrm{H}_{2} \mathrm{O}$} \\
\hline d DRH found when $\mathrm{i}$ & cluding $\mathrm{NaNO}_{3} \cdot \mathrm{Na}_{2}$ & $\mathrm{H}_{2} \mathrm{O}$ & & & & & & \\
\hline
\end{tabular}

\subsubsection{Water activity}

A method is required which relates the water activity of the solution to both ambient conditions and the chemical composition of the aerosol. At equilibrium, it can be shown that, over a flat surface, the water activity equals the ambient relative humidity in the sub-saturated humid environment (see Seinfeld and Pandis, 1998).

$a_{w}=R H$

When treating a curved surface this relationship is no longer valid. This is discussed in Sect. 3.

Hence, for each $R H$ the water activity of any liquid aerosol solution is fixed. There are numerous techniques for calculating the water content associated with an aerosol that are discussed and reviewed in the literature to varying extents (Chan et al., 1992; Cohen et al., 1987a, b; Pilinis, 1999). Recently, techniques for calculating the water activity from hygroscopicity data has been presented and used directly for calculating CCN activation (Kreidenweis et al., 2005). Similarly, Kiss and Hansson (2004) calculated water activity from osmolality which could then be used directly in the Kohler equation. Perhaps the most widely used predictive mixing rule is that defined by Stokes and Robinson (1966), namely the ZSR (Zdanovski-Stokes-Robinson) mixing rule. It has been shown that the ZSR relationship has been able to predict the water content of supersaturated aqueous aerosols quite well (Chan et al., 2000; Ha et al., 2000) and has been incorporated into existing aerosol models: EQUISOLV II - Jacobson (1999b); ISORROPRIA - Nenes et al. (1998); AIM - Wexler and Seinfeld (1991); SCAPE II - Meng et al. (1995); GFEMN - Ansari and Pandis (1999). The generalised form presented in most publications (e.g. Jacobson, 1999a) is given by Eq. (11).

$W=\sum \frac{M_{i}}{m_{i o}\left(a_{w}\right)}$

$\mathrm{W}$ is the total water content, $M_{i}$ is the number of moles of the solute present and $m_{i o}\left(a_{w}\right)$ the molality at a given $R H$ $\left(a_{w}\right)$. Only data for single solute solutions are required to predict the water content of a mixture. Such data is available in the literature (Cohen et al., 1987a, b; Jacobson, 1999a; Tang, 1997; Tang and Munkelwitz, 1994). However, it must be remembered that the ZSR is based on semi-ideality. Attempts have been made to improve the traditional ZSR relationship and account in some manner for deviations from semi-ideality (e.g. Clegg et al., 2003; Tang, 1997). However, despite the success of the extended relationship to model various systems, it is difficult to assess its success in more complex mixtures. In addition, one is severely limited by the data available that includes lack of treatment of the $\mathrm{NH}_{4}^{+}-\mathrm{NO}_{3}^{-}$$\mathrm{SO}_{4}^{2-}$ system. Furthermore, using such a mixing rule with the current activity coefficient model may introduce some inconsistencies (Ansari and Pandis, 1999). Within the minimisation scheme, one cannot rely solely upon the GibbsDuhem relationship for calculating the gradient of the Gibbs energy surface since varying solute concentrations influences the water content directly using relationship (11). To circumvent these problems and provide a more accurate estimation of the inorganic aerosol water content, the solvent activity model of Clegg et al. (1998a, b) is used here. In this way the interactions between the respective solutes, and not just the solute/solvent interactions, are treated explicitly. The activity of water is calculated on a mole fraction scale:

$a_{w}=f_{w} x_{w}$

\subsection{Solids}

Following GFEMN, the current model uses adjusted energies of formation for solid components $\left(\Delta G_{f}^{o}\right)$. It was found that in order to match deliquescence behaviour to that reported experimentally, the energies of formation for each solid had to be adjusted slightly. The results are shown in Table 1, and discussed in Sect. 6.1, with regard to model sensitivity. Such energies are also used to model multi-component deliquescence behaviour as in GFEMN. Table 2 shows the reported DRH points for four mixtures and comparisons with 

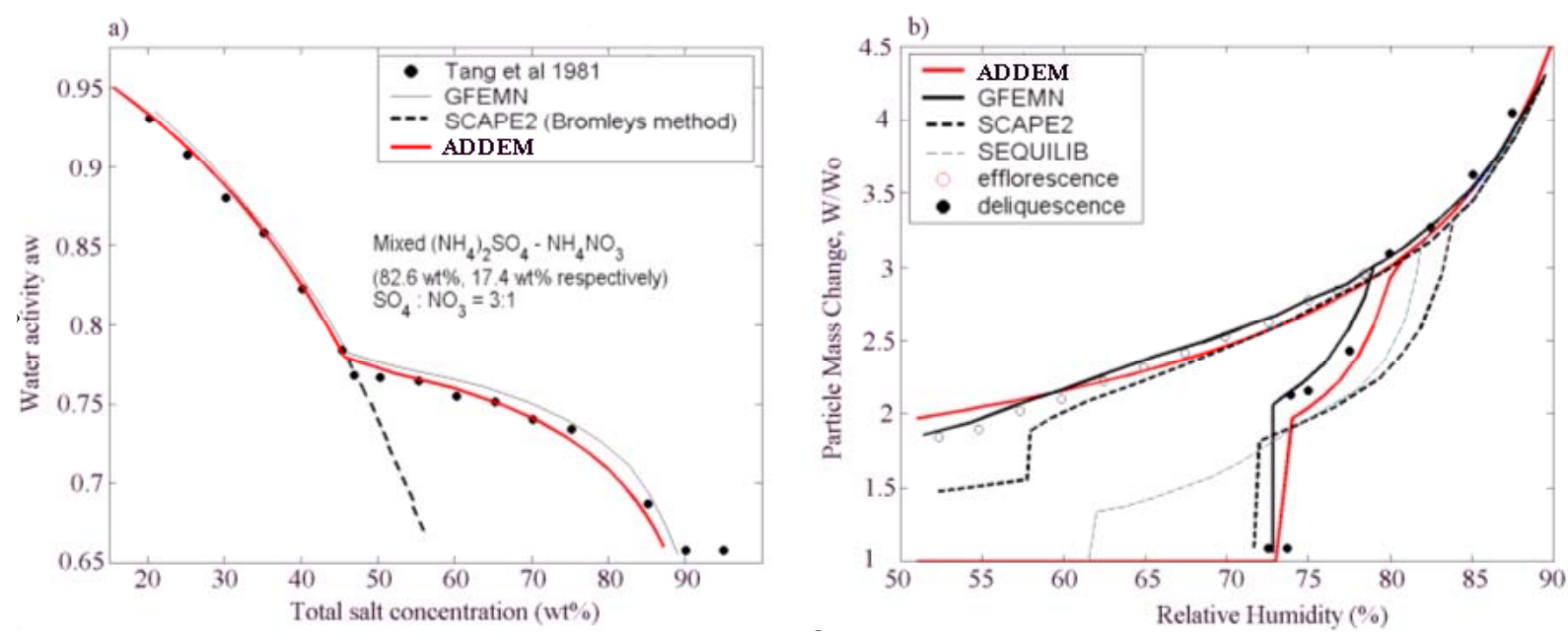

Fig. 2. (a) Water activity as a function of total solute concentration at $25^{\circ} \mathrm{C}$ for a mixed $\left(\mathrm{NH}_{4}\right)_{2} \mathrm{SO}_{4}-\mathrm{NH}_{4} \mathrm{NO}_{3} \mathrm{particle}\left(\mathrm{SO}_{4}: \mathrm{NO}_{3} 3: 1\right)$. GFEMN and SCAPE2 results taken from Ansari and Pandis (1999). Experimental data taken from Tang and Munkelwitz (1981). (b) Particle mass change at $25^{\circ} \mathrm{C}$ for a mixed $\mathrm{Na}_{2} \mathrm{SO}_{4}-\mathrm{NaCl}$ (equimolar) particle. GFEMN, SCAPE2 and SEQUILIB results taken from Ansari and Pandis (1999).

experimental data and four other available models, including AIM online (Clegg et al., 1998a, b). The ability of the model to reproduce measured behaviour is shown in Figs. 2a and b, along with comparisons of other models.

\subsection{Complex salts}

The majority of models available do not take double or hydrated salts into account. There is contrasting evidence in the literature for their importance. Experimental evidence has shown that aerosols may exist in dry states that are composed of complex or hydrated salts. Stelson and Seinfeld (1982) showed that the double salt $2 \mathrm{NH}_{4} \mathrm{NO}_{3}$. $\left(\mathrm{NH}_{4}\right)_{2} \mathrm{SO}_{4}$ is present over a small $R H$ range (0.63-0.66) for the mixed $\mathrm{NH}_{4} \mathrm{NO}_{3} /\left(\mathrm{NH}_{4}\right)_{2} \mathrm{SO}_{4}$ particle. Similarly, Harrison and Sturges (1984) provide evidence of the same salt. In light of this, the equilibrium model treats various double salts. The information regarding the temperature dependent energies of formation was taken as polynomial fits from AIM online by matching given results for set mixed systems.

Hydrated salts are those salts to which water is chemically bound. Pilinis et al. (1989) note that $\mathrm{Na}_{2} \mathrm{SO}_{4}$ is the only inorganic salt present in atmospheric aerosols that has bound water associated with it. Tang (1997) also discusses the behaviour of sodium decahydrate $\left(\mathrm{Na}_{2} \mathrm{SO}_{4} \cdot 10 \mathrm{H}_{2} \mathrm{O}-\right.$ its stable form). It is noted that under ambient conditions, a supersaturated solution droplet at room temperature rarely crystallises to form the decahydrate. Instead, it crystallises into an anhydrous particle (no water) and obtains a lower deliquescence relative humidity as a result. Also mixed salt particles containing $\mathrm{Na}_{2} \mathrm{SO}_{4}$ are not observed to form hydrates (Tang, 1997). However, upon inclusion into the equilibrium model, it is clear that the thermodynamics show it may be the most stable form under certain conditions. Wexler and Clegg (2002), in developing AIM online, analysed the importance of double salts in the atmosphere. They found that, for a mixed $\mathrm{NH}_{4}-\mathrm{SO}_{4}-\mathrm{NO}_{3}-\mathrm{H}_{2} \mathrm{O}$ system, model calculations which do not include double salt formation predict an aqueous phase to persist until lower relative humidities. This has implications for light scattering properties for example, and mass transfer calculations for gases equilibrating with the aerosol phase. The equilibrium constants for these salts are a function of relative humidity (water vapour pressure), and there is a dissociation pressure associated with each salt (Crocker et al., 1997). Applied to the equilibrium model, this translates to a relative humidity dependent Gibbs free energy of formation. Thus, there is a point at which the dehydrated salt is more stable than its anhydrous form and vice versa. Such dependent fits were taken from AIM online, again by matching up energies required to produce the same results for certain mixed systems. An example is shown in Fig. 3. The complex salts treated here include $\mathrm{Na}_{2} \mathrm{SO}_{4} \cdot 10 \mathrm{H}_{2} \mathrm{O}, \quad \mathrm{NaHSO}_{4} \cdot \mathrm{H}_{2} \mathrm{O}, \quad \mathrm{NaNO}_{3} \cdot \mathrm{Na}_{2} \mathrm{SO}_{4} \cdot \mathrm{H}_{2} \mathrm{O}$, $(\mathrm{Na})_{2} \mathrm{SO}_{4} \cdot\left(\mathrm{NH}_{4}\right)_{2} \mathrm{SO}_{4} \cdot \mathrm{H}_{2} \mathrm{O}, \quad \mathrm{NH}_{4} \mathrm{NO}_{3} \cdot \mathrm{NH}_{4} \mathrm{HSO}_{4}$, $2 \mathrm{NH}_{4} \mathrm{NO}_{3} \cdot\left(\mathrm{NH}_{4}\right)_{2} \mathrm{SO}_{4}$ and $3 \mathrm{NH}_{4} \mathrm{NO}_{3} \cdot\left(\mathrm{NH}_{4}\right)_{2} \mathrm{SO}_{4}$.

Using the features discussed in Sect. 2, and highlighted in portion 'a)' of Fig. 1, it is now possible to construct an equilibrium model that neglects the Kelvin effect. However, a significant fraction of aerosols may populate the sub $100 \mathrm{~nm}$ region. Thus to adequately model the aerosol population, the curvature effect must be taken into account. The following section provides a way of treating the Kelvin effect in combination with the thermodynamic model described previously. 


\section{Curvature (the Kelvin effect)}

For a curved surface there are two competing effects defining equilibrium. The Raoult, or solute effect already treated in the equilibrium model described earlier acts to decrease the equilibrium pressure required. However, for a curved surface, the equilibrium pressure of component $\mathrm{A}$ is greater than that required for a flat surface as described by the Kelvin equation:

$p_{A}=p_{A}^{o} \exp \left(\frac{2 \sigma_{w s} v_{A}}{R T r_{d r o p}}\right)$

where $p_{A}$ and $p_{A}^{o}$ are the equilibrium pressures over a curved and flat drop, respectively, $\sigma_{w s}$ is the surface tension of the solution, $v_{A}$ is the partial molecular volume of component ' $A$ ', $R$ the universal gas constant, $T$ the temperature, and $r_{\text {drop }}$ the droplet radius. Combining these two competing effects leads to the well-known Kohler equation that provides the equilibrium condition for water vapour over a solution droplet in both the sub and supersaturated humid environment. There are many ways of deriving this relationship and the reader is referred to various sources in the literature (Chylek and Wong, 1998; Pruppacher and Klett, 1997; Seinfeld and Pandis, 1998):

$$
R H=a_{w} \exp \left(\frac{2 v_{w} \sigma_{w s}}{R T r_{d r o p}}\right)
$$

Thus at equilibrium over a curved surface the activity of water does not simply equal the ambient $R H$.

\subsection{Model treatment of the Kelvin effect}

Whilst the available equilibrium models have been built to treat the ionic interaction of the inorganic fraction with varying levels of accuracy, few treat the effect of curvature on the aerosol composition. The Kelvin effect may be neglected on particles larger than $100 \mathrm{~nm}$, though not treating it in general restricts the range of applicability of the aerosol model. Errors associated with this neglect also propagate through to any additional mass transport calculations made. As stated in the introduction, the models that do treat the Kelvin effect do so using different approaches. These include utilising the Gibbs-Thomson equation for each appropriate component in KEQUIL and assumptions of proportionality between the bulk and surface phase utilising the method of Suarez et al. (1989) in the model of Ming and Russell (2002). Another formal treatment would include the surface term in the Gibbs energy summation. However, as stated by Chylek and Wong (1998), this approach provides more opportunities to obtain inaccurate results when various terms appearing in the equations are not treated in a consistent manner. Indeed, using the results of Wilemski (1984) and Reiss and Koper (1995), the authors point out that a fully consistent thermodynamic treatment leads to the derivation of the original Kohler equation that provides the correct equilibrium

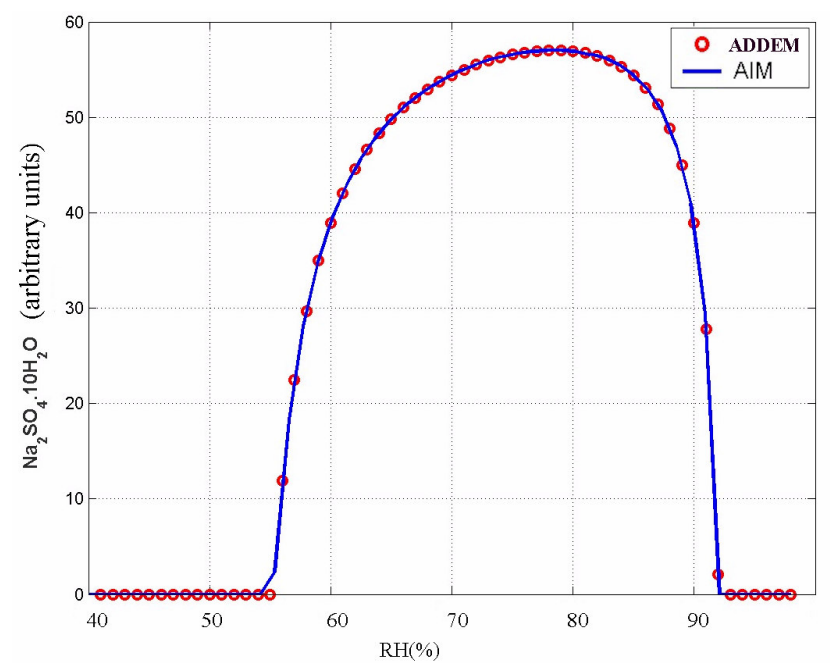

Fig. 3. Predictions for gradual solid precipitation for $\mathrm{Na}_{2} \mathrm{SO}_{4} \cdot 10 \mathrm{H}_{2} \mathrm{O}$, as a function of relative humidity, for a mixed $\mathrm{Na}_{2} \mathrm{SO}_{4}-\mathrm{HCl}$ system and comparison with AIM online (Clegg et al., 1998a, b). Relative composition $\mathrm{Na}_{2} \mathrm{SO}_{4}: \mathrm{HCl}$ of 8:1. No other solids are allowed to precipitate during calculations.

condition for a solution droplet. Sole use of the Kohler equation to calculate the complete phase equilibrium composition for multiple solutes in the sub-saturated regime cannot be justified due to the invalid assumption of infinite solubility used in its derivation. Indeed, modifications are continually being made in order to make this simple formulation more applicable to hygroscopic growth regions (e.g. Bilde and Svenningsson, 2004; Laaksonen et al., 1998; Shulman et al., 1996). However, one can combine the thermodynamic model and the equilibration of water governed by the simple Kohler equation in order to find a solution pertaining to this new definition of equilibrium.

This way one can also utilise a wide variety of surface tension models, the more complicated of which often treat the surface/bulk concentration relations explicitly by using various definitions of the surface phase and appropriate activity models.

As already stated, for a flat solution the activity of water equals the $R H$ at equilibrium. However, the simple Kohler equation shows that for a curved surface the activity of water is equal to the $R H$ divided by the Kelvin term. The model thus needs to find a solution pertaining to this new definition of equilibrium.

For each water content there is an associated composition (liquid and solid) and water activity at equilibrium. Similarly, the physical characteristics of the composition (a radius derived from assumed particle sphericity) define a new Kelvin factor through the use of appropriate surface tension models and density mixing rules. Since one is dealing with a one-dimensional problem (water equilibration) with a unique solution one can thus employ a bisection approach to find the 


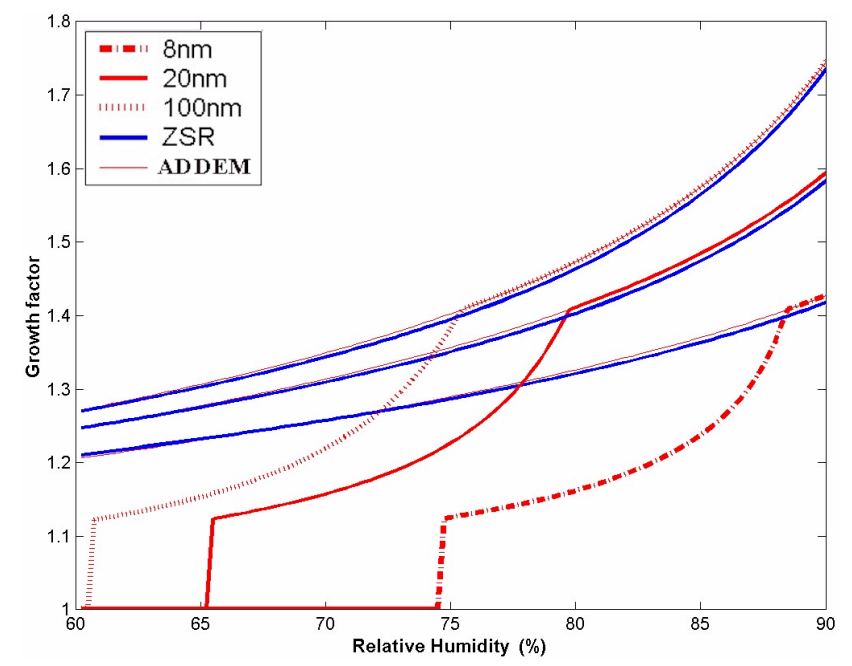

Fig. 4. Influence of curvature on aerosol composition for a mixed equimolar $\left(\mathrm{NH}_{4}\right)_{2} \mathrm{SO}_{4}-\mathrm{NH}_{4} \mathrm{NO}_{3}$ aerosol at $25^{\circ} \mathrm{C}$. The model output (ADDEM) is from the scheme described in this paper including diameter dependence. The three dry diameters chosen are 8, 20 and $100 \mathrm{~nm}$. Also shown are the growth factor predictions for a ZSR analogue growth factor model. Both utilise the mass fraction mixing rule of Tang (1997) for calculating the solution and dry densities.

required root of Eq. (14). Hence, a method with guaranteed convergence is used when the root has been bracketed accordingly. The variable involved in this bisection approach controls the water content, thus the water activity. In this manner, the aerosol is forced toward a dry state, using a step length defined by the user, and a solution to relation (14) found if indeed there is one. For conditions where solid precipitation may occur (e.g. gradual deliquescence behaviour) or any complex formation (bisulphate ion) then the minimum energy associated with each new iteration must be found. Therefore, the energy minimisation scheme is housed within the bisection method here. This is shown in section 'b)' of Fig. 1. Since water is a free variable in this minimisation, one requires a technique of controlling the bounds of aerosol water content. This is achieved by changing the energetics of the system through the energy of formation for liquid water (the condition $\mu_{\text {liquid }}=\mu_{\text {gas }}$ defines how much water is associated with the aerosol). For solutions with no solid precipitation or bisulphate formation one can simply vary the water content directly (an initial guess given by the ZSR relationship), bypassing the energy minimisation scheme, until the new solution is found.

\subsection{Altering composition with curvature}

One can therefore predict the effect of curvature on solid precipitation as shown in Fig. 4. First, the minimisation scheme is used to check if a solid aerosol is the most stable state for a 'flat' system at a given composition and ambient condi- tions. If a dry aerosol is returned then the diameter dependent model need not be applied since the effect of curvature only acts to increase the equilibrium pressure of water, thus driving the aerosol toward a solid state. Otherwise, the diameter dependent scheme is used. There may be some additional steps required around the deliquescence point of the aerosol. The initial step in the bisection approach may be too great, predicting a completely solid aerosol that causes numerical instability in the bisection approach. This may also not be the most stable state of the aerosol for a given size. In order to refine the search, smaller step lengths are used and the solution space defined by the initial step length is searched to see if the difference converges to zero. If it does then the normal bisection approach may be used. If not then a solid aerosol is predicted.

Clearly the effect of curvature will also influence the aqueous composition. Whilst such an effect can be encompassed into a growth factor model that relies upon experimental data of molality versus $a_{w}$, again the influence of other solutes is not treated in such schemes. Similarly, such effects propagate through to the prediction of equilibrium pressures above the aerosol for mass transfer predictions.

Hence, one can now build a framework for calculating the diameter dependent equilibrium composition of an aerosol of known composition, size and given ambient conditions. It is now necessary to define how one can calculate the mixture properties for use in the Kelvin equation, before comparisons with other diameter dependent models and more simple parameterisations.

\section{Mixture parameters}

In order to calculate mixtures properties, various models for the chemical and physical characteristics had to be chosen.

\subsection{Surface tension}

All surface tension predictions made here use bulk relationships. Several authors have noted the inadequacy of bulk surface tension for finite molecule systems (Girshick and Chiu, 1990; Russell and Ming, 2002; Wilemski, 1995). However the work of Fisher and Israelachvili (1979) suggests that bulk relationships may be appropriate. The variation of surface tension with aerosol size for will not be reviewed or analysed here.

For single salt systems empirical fits are commonly used, though there can be inconsistencies between different fits that inevitably introduce sensitivities to growth factor calculations (see Hameri et al., 2000). For multi-component systems, three groups of calculation have been presented in the literature (Hu and Lee, 2004). These include simple additive methods and conventional thermodynamic methods based on the Gibbs adsorption equation. It is useful to provide brief examples of such techniques here before the scheme used in 
this model is described. The simple additive methods, such as that of Chen (1994), are based on the assumptions that the difference between the surface tension of electrolyte solutions and that of water at the same temperature is proportional to the respective number of ions (Hu and Lee, 2004). The mixing rule of Chen (1994), used in various atmospheric applications (e.g. Brechtel and Kreidenweis, 2000a, b), is given as:

$\sigma_{w s}=\sigma_{w}+\frac{M_{w} \sum_{i} m_{i}\left(\sigma_{i}^{\prime}-\sigma_{w}\right)}{1+M_{w} m_{s}}$

where $\sigma_{w s}$ is the solution surface tension, $\sigma_{w}$ the surface tension of pure water, $\sigma_{i}^{\prime}$ the apparent surface tension of solute $i$ and $m_{s}$ the overall solution molality. A more rigorous derivation has been provided by $\mathrm{Hu}$ and Lee (2004) which leads to a simple mixing rule for the surface tension of electrolyte solutions at constant ionic strength:

$\sigma_{w s}=\sum_{i} y_{i} \sigma_{i}^{o}$

where $y_{i}$ is the ionic strength fraction of solute $i$ and $\sigma_{i}^{o}$ the surface tension of a binary solution of solute $i$ at the ionic strength of the mixture. The authors report improved predictive capability for 26 concentrated multi-component electrolyte solutions at different temperatures, even compared with a thermodynamic model ( $\mathrm{Li}$ et al., 1999). However, binary data may not extend into the concentration ranges required for moderate to highly concentrated mixed solutions. In this instance, an approximate value has to be used. There are thermodynamic techniques available that have strict derivations and use the activity of solutes present in the aerosol. A common approach consists combining thermodynamic relations together with an adsorption model. In the model presented by Li and Lu (2001), the authors combined the Gibbs dividing surface, the Langmuir adsorption equation and an appropriate model for calculating activity coefficients in mixed solutions:

$\sigma_{w s}=\sigma_{w}+R T \sum_{i=1}^{k} \Gamma_{i}^{w o} \ln \left(1-\frac{k_{i} a_{i}}{1+\sum_{j} k_{j} a_{j}}\right)$

where $\Gamma_{i}^{w o}$ is the saturated surface excess of solute $i$ (tabulated), $k_{i}$ the adsorption equilibrium constant for solute $i$ (tabulated) and $a_{i}$ the activity of component $i$.

The authors claim the model is able to represent surface tensions up to concentrations of $36 \mathrm{M}$ where an average absolute percentage deviation from experimental data for 45 single solutes of 0.47 was reported. In addition, it was used to predict surface tensions of 11 binary and five ternary mixtures with an average absolute percentage deviation from experimental data of 1.69. The two models presented in this work for mixed electrolyte solutions have slightly different derivations. The first is based on the assumption that there is no interaction or competing adsorption between electrolytes at the interface. The second model shown here assumes that it may be preferable to consider competing adsorption between the electrolytes at the interface at higher concentrations.

Despite no significant difference between each model, any aerosol model should be applicable to a wide range of troposheric conditions. Since this includes varying temperature and relative humidity, the thermodynamic model of $\mathrm{Li}$ and Lu (2001) has been used in this equilibrium model and uses the same activity model as the bulk phase to maintain some consistency. The sensitivity to the choice of surface tension model is discussed in more detail in Sect. 7.

\subsection{Density}

In order to calculate the radius in Eq. (13), the density of the mixed inorganic solution must be calculated. There are a few techniques available. The simple combination rules have been reviewed briefly in the literature (e.g. Tang, 1997), where a basic volume additivity rule was found to be adequate for most of the systems studied. A mixed solution density can be calculated using only the binary solution data using the following rule:

$\frac{1}{\rho_{s o l}}=\sum_{i} \frac{X_{i}}{\rho_{o i}}$

where $X_{i}$ is the dry solute mass fraction for compound $i$ and $\rho_{o i}$ the binary solution density for compound $i$ at the solute concentration of the mixture. The binary data is available in the literature (Tang, 1997). Alternatively, one may replace the mass fraction but the mole fraction of the dry solute. However, the mass fraction mixing rule has been found to be more accurate (Tang, 1997).

It is now interesting to analyse diameter dependent phenomena and compare with other available techniques.

\section{Growth factor}

The hygroscopicity of an aerosol is often related to the directly measurable parameter known as the growth factor. This simply relates the change in diameter from one reference $R H$ to that at another:

$G F=d(R H) / d(d r y)$

where the dry state, $d(d r y)$, is often used as the reference diameter.

In order to calculate the wet diameter, volume additivity is assumed whereby the solution and dry solute are added together.

$V_{\text {aerosol }}=V_{\text {solid }}+V_{\text {solution }}$

For the dry solute density, the mass fraction weighted mixing rule of Tang (1997) is used. 
Table 3. Growth factor percentage deviations for various equimolar compositions at $25^{\circ} \mathrm{C}$. Percentage deviations are calculated as the absolute value of $\left(\mathrm{GF}_{Z S R} / \mathrm{G}_{\text {Thermo }}-1\right) * 100 \%$.

\begin{tabular}{|c|c|c|c|c|c|c|c|c|c|c|c|c|}
\hline \multirow[t]{2}{*}{ Components } & \multicolumn{12}{|l|}{$\mathrm{RH}$} \\
\hline & $40 \%$ & & $50 \%$ & & $60 \%$ & & $70 \%$ & & $80 \%$ & & $90 \%$ & \\
\hline$\left(\mathrm{NH}_{4}\right)_{2} \mathrm{SO}_{4}-\mathrm{NH}_{4} \mathrm{NO}_{3}$ & 0.495 & 0.010 & 0.993 & 0.002 & 1.214 & 0.002 & 1.402 & 0.007 & 1.404 & 0.010 & 1.075 & 0.011 \\
\hline$\left(\mathrm{NH}_{4}\right)_{2} \mathrm{SO}_{4}-\mathrm{NaCl}$ & 1.021 & 0.003 & 0.761 & 0.009 & 1.248 & 0.003 & 1.425 & 0.002 & 1.718 & 0.002 & 2.260 & 0.013 \\
\hline $\mathrm{Na}_{2} \mathrm{SO}_{4}-\mathrm{NaNO}_{3}$ & 0.958 & 0.017 & 0.765 & 0.015 & 0.521 & 0.012 & 0.271 & 0.008 & 0.027 & 0.001 & 0.729 & 0.018 \\
\hline$\left(\mathrm{NH}_{4}\right)_{2} \mathrm{SO}_{4}-\mathrm{NaCl}-\mathrm{H}_{2} \mathrm{SO}_{4}$ & 6.959 & 0.092 & 6.458 & 0.091 & 5.508 & 0.085 & 4.231 & 0.073 & 2.720 & 0.058 & 1.098 & 0.040 \\
\hline$\left(\mathrm{NH}_{4}\right)_{2} \mathrm{SO}_{4}-\mathrm{NaNO}_{3}-\mathrm{H}_{2} \mathrm{SO}_{4}$ & 7.296 & 0.086 & 7.800 & 0.090 & 7.085 & 0.087 & 5.713 & 0.076 & 3.875 & 0.059 & 1.971 & 0.043 \\
\hline
\end{tabular}

\subsection{Growth factor parameterisations}

Rather than define the water uptake through strict thermodynamics, it is possible to derive much simpler relationships that can also utilise the Kohler equation, thus providing diameter dependent growth factor parameterisations. Using bulk empirical data, the growth factor of an aqueous aerosol can be defined quite easily using assumptions of particle sphericity and volume additivity. For completely soluble particles the growth factor can be expressed as (Swietlicki et al., 1999):

$G F=\left(\frac{\rho_{s}}{\rho_{s o l}}\left[1+\left(m M_{s}\right)^{-1}\right]\right)^{1 / 3}$

where $\rho_{s}$ is the dry density, $\rho_{s o l}$ the solution density, $m$ the solution molality and $M_{s}$ the molecular weight.

Similarly for mixed solutes, a method following Malm and Kreidenweis (1997) can be used by evoking the principles of the ZSR relationship. In this way, the growth factor of the mixed solute is calculated using only data from the binary systems. Cruz and Pandis (2000) use a similar relationship to analyse data from mixed binary inorganic/organic systems. As with the ZSR relationship, such multi-component schemes are based on semi-ideality. Whilst uncoupled inorganic/organic thermodynamic models deal with the interactions taking place within the two separate fractions, this method only treats the numerous solvent/solute interactions.

If relying solely on density information for calculating growth factors, for a diameter dependent model one can utilise the same approach as that used with the thermodynamic scheme. In this instance, the solute mass fraction is varied and the process becomes iterative until the Kelvin term converges toward a solution within a set tolerance level.

Thus, it is now possible to compare two diameter dependent growth factor models that approach the same problem differently. This is shown in Fig. 4 for an equimolar $\left(\mathrm{NH}_{4}\right)_{2} \mathrm{SO}_{4}: \mathrm{NH}_{4} \mathrm{NO}_{3}$ system. The ZSR model uses the method invoked by Malm and Kreidenweis (1997) for mixed solutes whereas the thermodynamic model is that presented in this paper. For the thermodynamic predictions, only solid-liquid equilibrium is treated, whereas the ZSR model can only treat purely aqueous systems here. For comparative purposes the ZSR model used the same growth factor for the binary systems as the thermodynamic model, and in both cases the mass fraction density scheme of Tang (1997) was used for calculating multi-component solution densities. Whilst the difference between the two schemes in Fig. 4 is small, the advantage of using a thermodynamic approach is clear. Indeed, it is possible to predict stepped deliquescence behaviour as the solubility of one salt is influenced by the presence of other solutes. For comparisons with laboratory and field data, the inclusion of solid formation extends the range of model applicability. Table 3 shows percentage deviations (here defined as $\left.\left(\mathrm{GF}_{Z S R} / \mathrm{GF}_{\text {thermo }}-1\right) \times 100 \%\right)$ between the two approaches for some binary and ternary mixed systems, neglecting the influence of curvature. Interestingly, for the binary mixtures the deviations are not particularly large, ranging from 0.02 to $2.25 \%$. In addition, the general trend is that as the solution becomes more concentrated the deviations tend to increase, which is down to the neglect of solute-solute interactions within the ZSR relationship. For all given systems at higher relative humidity, the corresponding absolute growth factor difference between the two models is likely to be within the experimental uncertainty of the HTDMA. For the ternary systems, the deviations are larger. Again, this is down to the neglect of the solute-solute interactions. In this instance, the thermodynamic model can explicitly deal with the partitioning of the bisulphate ion, whilst the ZSR cannot. As shown in the table, for a relative humidity down to $40 \%$, this introduces growth factor deviations of around $7 \%$, with a corresponding absolute value of around 0.1 . Such deviations are likely to be outside the experimental uncertainty of the HTDMA. Thus for such ambient conditions in which solute concentrations increase, and for larger multi-component systems, the choice of growth factor model scheme is likely to be important. Whilst ZSR has been used to analyse mixed inorganic/organic systems with relative success (Cruz and Pandis, 2000), it is unclear as to the improvement one gains when treating the system using an uncoupled thermodynamic approach. Indeed, for mixed aqueous systems where solid precipitation cannot be treated thermodynamically, this should be the focus of future work. It must also be pointed out that an explicit treatment of the system thermodynamics allows one to extend predictions into the super-saturated humid regime, thus enabling one to analyse 
the aerosol cloud nucleating capabilities. Indeed, the parameterisations given above were designed specifically to model sub-saturated hygroscopic growth.

\section{Deliquescence of small particles}

Since the size of the aerosol particles can range from just a few molecules to particles with radii larger than $100 \mu \mathrm{m}$, it is important to understand the role the surface effects have on the deliquescence process by which small drops are formed (Mirabel et al., 2000). There have been few attempts to predict the influence of curvature on the hygroscopic properties, specifically in relation to the change in deliquescence patterns. There are various complicating features surrounding the point of deliquescence. It is the norm to consider the transition from an uncoated dry aerosol to a dissolved salt droplet. Whilst several studies have shown that it may be more suitable to consider the transition from a wetted particle to a dissolved droplet (Finlayson-Pitts and Hemminger, 2000; Ghosal and Hemminger, 1999; Weis and Ewing, 1999) such features will not be further analysed here, the adjusted energies of formation used to match experimental data inevitably subsuming a lot of these characteristics.

Mirabel et al. (2000) developed a model to predict the prompt deliquescence, and its dependence on particle size, for a generic crystal with an ideal solution. More recently, Russell and Ming (2002) developed a similar model for treating wetted particles and non-ideal effects. Similarly, the same authors incorporated the curvature effect into a larger thermodynamic equilibrium model used to treat mixed inorganic/organic systems (Ming and Russell, 2002). Both techniques can be compared with the model described here. There is also some experimental data provided in the literature that can be used as a preliminary comparison (Hameri et al., 2000).

Using results from Russell and Ming (2002), the model described by these authors and that described here agree for a $15 \mathrm{~nm}\left(\mathrm{NH}_{4}\right)_{2} \mathrm{SO}_{4}$ particle, predicting the same shift in the deliquescent point to $88 \%$. This shows a predicted increase in the deliquescence point by $8 \%$ compared to the bulk data. Comparison between the two models for a $15 \mathrm{~nm} \mathrm{NaCl}$ particle also shows very good agreement for the altered DRH (Russell and Ming, 2002: 83\%, Model 81.6\%).

Figure 5 shows a comparison between the model described here, that of Ming and Russell (2002), bulk data, and $100 \mathrm{~nm}$ data for both $\mathrm{NaCl}$ and $\left(\mathrm{NH}_{4}\right)_{2} \mathrm{SO}_{4}$ aerosols. The model predictions, neglecting the Kelvin effect, compare very well with the bulk data as one might expect. Again the two separate curved models agree very well for both aerosol types, each predicting an increase in the DRH for $100 \mathrm{~nm}$ of the same magnitude (Ming and Russell (2002) $\left(\mathrm{NH}_{4}\right)_{2} \mathrm{SO}_{4}-$ $82 \%, \mathrm{NaCl}-76.7 \%$; this model $\left(\mathrm{NH}_{4}\right)_{2} \mathrm{SO}_{4}-81.5 \%, \mathrm{NaCl}-$ $76.4 \%$ ). The measurements of Cruz and Pandis (2000) differ from those of Hameri et al. (2002) for $100 \mathrm{~nm}$ aerosol, be-

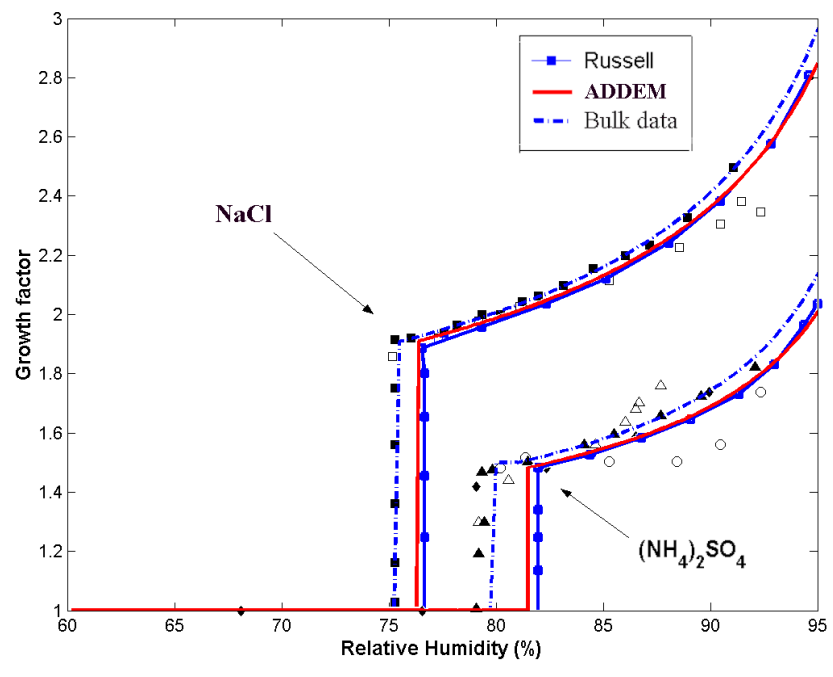

Fig. 5. Hygroscopic growth predictions for $100 \mathrm{~nm} \mathrm{NaCl}$ and $\left(\mathrm{NH}_{4}\right)_{2} \mathrm{SO}_{4}$, comparisons with experimental data and other theoretical results. Theoretical results taken from Ming and Russell (2002) labelled 'Russell'. Bulk data: Dashed lines are model predictions, $\mathrm{NaCl}$ (solid square) (Tang et al., 1986), $\left(\mathrm{NH}_{4}\right)_{2} \mathrm{SO}_{4}$ (solid triangle) (Tang and Munkelwitz, 1994). $100 \mathrm{~nm}$ data: $\mathrm{NaCl}$ (open square - Cruz and Pandis, 2000), $\left(\mathrm{NH}_{4}\right)_{2} \mathrm{SO}_{4}$ (open circle - Cruz and Pandis, 2000, open traingle - Hameri et al., 2002). $50 \mathrm{~nm}$ data: $\left(\mathrm{NH}_{4}\right)_{2} \mathrm{SO}_{4}$ (solid diamond - Hameri et al., 2000).

tween relative humidities of $85 \%$ and $99 \%$, by between $20 \%$ and $30 \%$ as pointed out by Ming and Russell (2002), both model predictions lying between the two.

For surface tension predictions, the binary data of Pruppacher and Klett (1997) was used for $\left(\mathrm{NH}_{4}\right)_{2} \mathrm{SO}_{4}$ and the model of Chen (1994) for $\mathrm{NaCl}$. The lack of any change in DRH for the sub $100 \mathrm{~nm}\left(\mathrm{NH}_{4}\right)_{2} \mathrm{SO}_{4}$ aerosol studied by Hameri et al. (2000) is an interesting result. Nonetheless, both models predict an increase should occur, and as stated by Russell and Ming (2002), additional experiments might be able to not only confirm the increase in deliquescence relative humidity with decreasing particle size, but also to allow sizedependent surface tension measurements to be made. The agreement between the model presented here (Kohler equation) and the model of Russell and Ming (2002) (Explicit energy derivative formulation) is encouraging considering the different level of complexity from both approaches.

\section{Sensitivity studies}

The equilibrium model already described is subject to various sensitivities created by the introduction of empirical parameters and choice of calculation techniques for multiple physical/chemical characteristics of the aerosol. For the general equilibrium model, these include important thermodynamic parameters. For a curved model, these also include 


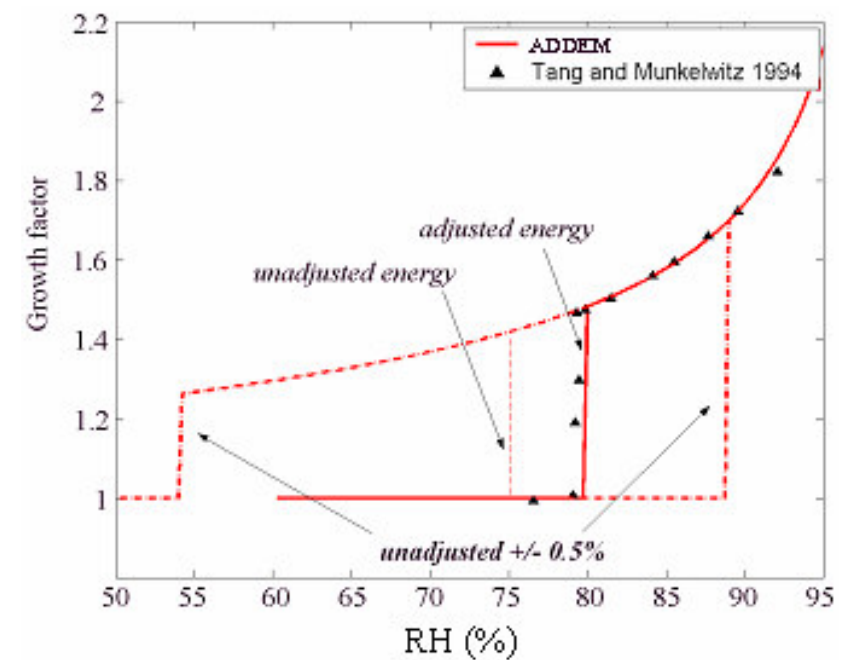

Fig. 6. Deliquescence growth curve for $\left(\mathrm{NH}_{4}\right)_{2} \mathrm{SO}_{4}-$ Sensitivity to Gibbs energy of formation for the salt.

surface tension and density calculations when treating the Kelvin effect. All are analysed here.

\subsection{Thermodynamic parameters}

\subsubsection{Energies of formation}

As with GFEMN, it was found that the equilibrium model was particularly sensitive to the energies of formation used for the different salts. Indeed, if the values tabulated in the literature were used, the model could not accurately reproduce known deliquescence behaviour. In light of this, and given that the experimental uncertainty in $\Delta G_{f}^{o}$ is more than $0.5 \%$ (Ansari and Pandis, 1999), the values of $\Delta G_{f}^{o}$ were adjusted and the required magnitude of these adjustments are shown in Table 1 along with those reported by Ansari and Pandis (1999). Figure 6 highlights the sensitivity of the model to the value used. For a deviation of only $0.5 \%$ either side of the reported value, the deliquescence relative humidity for a $\left(\mathrm{NH}_{4}\right)_{2} \mathrm{SO}_{4}$ particle ranges from 54 to $88 \%$. Thus, similar adjustments were made for all aerosol salts using the measured DRH data of Pilinis et al. (1995). Since aerosols may exist as multi-component particles, it is important to analyse the sensitivity of the model to using single adjusted energies of formation for multistage growth patterns. One can do this by using experimentally observed multistage growth patterns such as those provided by Tang (1997). The adjustment in $\Delta G_{f}^{o}$ for each solid component results in no need to adjust the values of $\Delta G_{f}^{o}$ for the ions or gaseous components.

However, unlike GFEMN, water is a free variable in this system thus requiring its own activity coefficient. This has been described in the text. Ultimately the water content is determined by the difference in chemical potentials between water in the gas and liquid phase. Thus, there is an inevitable

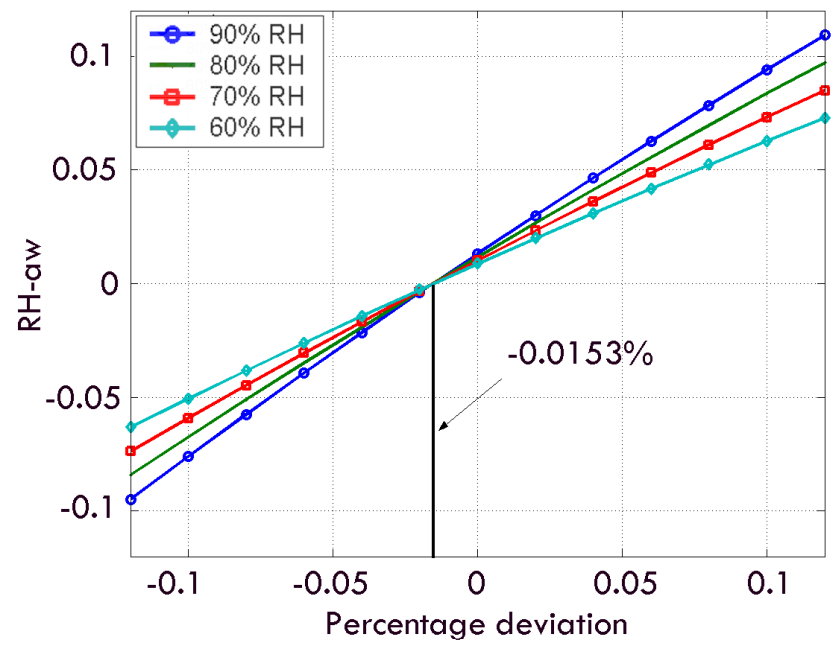

Fig. 7. Difference between equilibrium solution water activity and $R H(0-1)$ for various values of $\Delta \mathrm{G}_{f}^{o} \mathrm{H}_{2} \mathrm{O}(1)$. Percentage deviation is taken from the tabulated value of Ansari and Pandis (1999).

sensitivity to the value of $\Delta G_{f}^{o}$ chosen for liquid water. Using the value tabulated by Ansari and Pandis (1999), it was found that the activity of water did not equal the relative humidity at equilibrium. It is important to stress how sensitive this is to the calculated water content. Since water uptake is an exponential function of water activity, at high relative humidity any deviation from the equilibrium condition could have drastic consequences. This is best illustrated in Fig. 7. Here the difference between the relative humidity and water activity is shown for various deviations from the tabulated value of $\Delta G_{f}^{o}$. The figure also highlights how this relationship changes for different relative humidity. Clearly there is a large sensitivity, for a deviation of just $0.12 \%$ in $\Delta G_{f}^{o}$, a difference of 0.11 is found at $90 \% R H$. This translates to an aerosol with an equilibrium water activity of 0.79 , thus representing the water content at $79 \% R H$, roughly $50 \%$ the amount found at $90 \% R H$. The figure also shows that the sensitivity decreases at lower $R H$, which one would expect. Hence a value was derived for which the difference between $R H$ and $\mathrm{a}_{w}$ was negligible. A deviation of $-0.0153 \%$ was required, clearly within the uncertainty of $0.5 \%$ given for other parameters, the resulting value shown in Table 1 . Importantly, this was found to be independent of composition and relative humidity.

\subsection{Surface tension}

Clearly, the calculation of the Kelvin term is sensitive to the value of surface tension used. As the solution becomes more concentrated, it becomes less appropriate to use the bulk value for water. There are various options for dealing with both single and mixed solute systems. Hameri et al. (2000) analysed the sensitivity of different models for ammonium sulphate solutions, highlighting the inconsistency between 

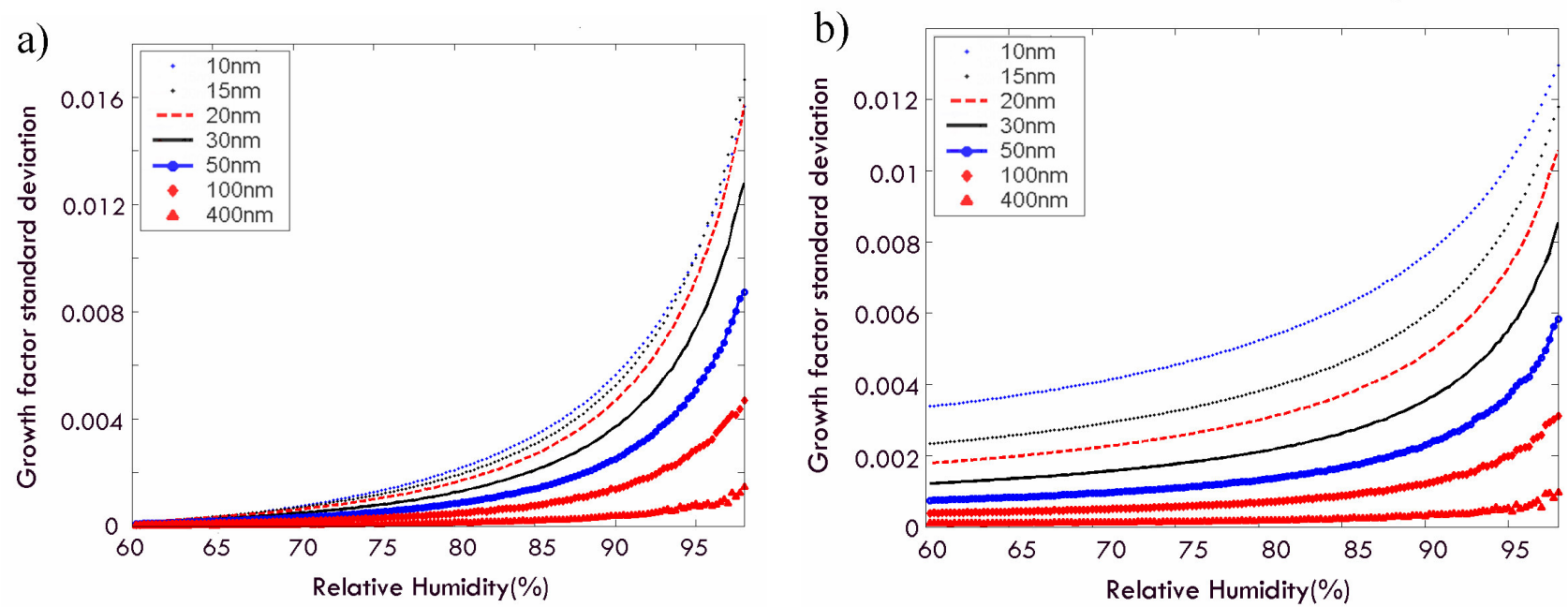

c)
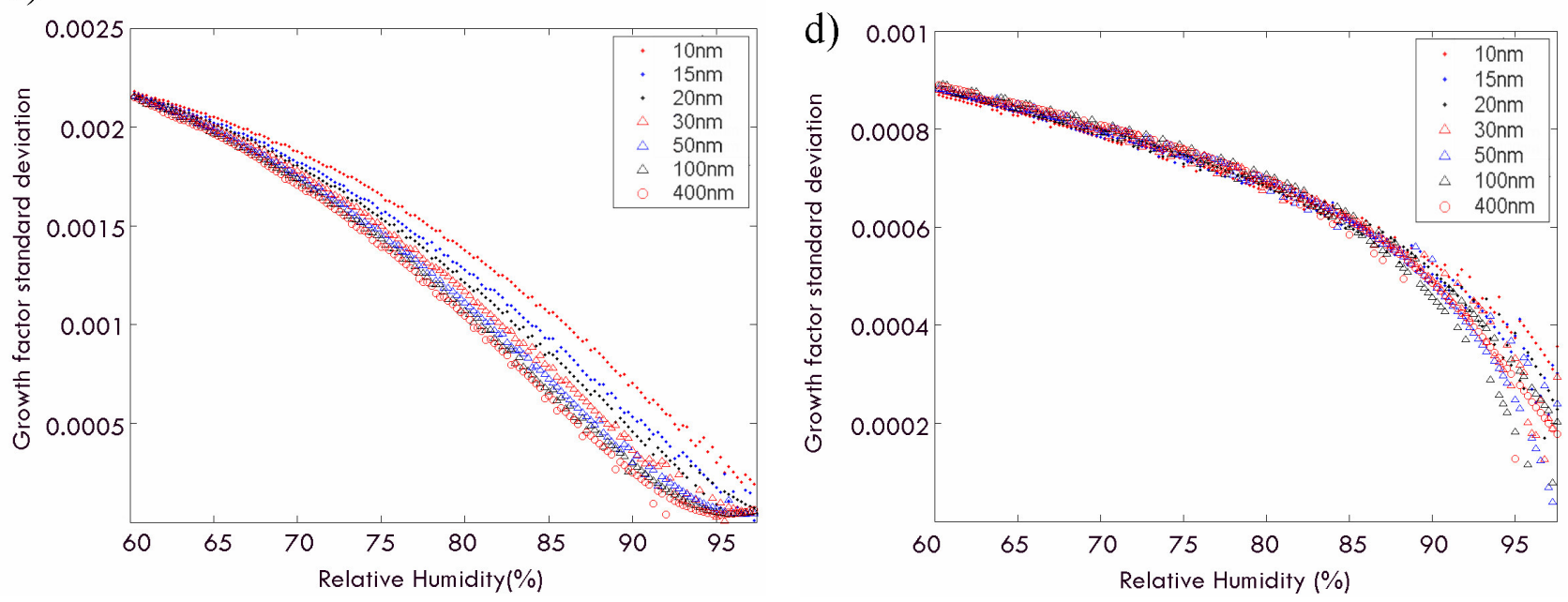

Fig. 8. (a) GF standard deviation for different dry diameters using 3 surface tension models for equimolar $\mathrm{NaCl}_{-}\left(\mathrm{NH}_{4}\right)_{2} \mathrm{SO}_{4}$ at $25^{\circ} \mathrm{C}$. (b) GF standard deviation for different dry diameters using 3 surface tension models for $\mathrm{H}_{2} \mathrm{SO}_{4}-\left(\mathrm{NH}_{4}\right)_{2} \mathrm{SO}_{4}$ particles at $25^{\circ} \mathrm{C}$. (c) $\mathrm{GF}$ standard deviation for different dry diameters using 3 solution density models for equimolar $\mathrm{NaCl}-\left(\mathrm{NH}_{4}\right)_{2} \mathrm{SO}_{4}$ particles at $25^{\circ} \mathrm{C}$. (d) $\mathrm{GF}$ standard deviation for different dry diameters using 3 solution density models for equimolar $\mathrm{H}_{2} \mathrm{SO}_{4}-\left(\mathrm{NH}_{4}\right)_{2} \mathrm{SO}_{4}$ particles at $25^{\circ} \mathrm{C}$.

them. They also found that as the dry diameter decreased, the sensitivity to the model chosen increased. A similar study for different binary fits will not be carried out here. Instead, the sensitivity to the choice of model used for dealing with mixed solutions is analysed for two separate mixed systems. Here, the dry diameters of 10,15, 20, 30, 50, 100 and $400 \mathrm{~nm}$ are used. The three surface tension models chosen have already been described in Sect. 4.1. Figure 8a shows the standard deviation in the calculated growth factor for an equimolar $\mathrm{NaCl} /\left(\mathrm{NH}_{4}\right)_{2} \mathrm{SO}_{4}$ aerosol at $298.15 \mathrm{~K}$ using the three different models. Here, the three separate surface tension models were used to obtain three different growth factor curves and the standard deviation between such results calculated. Clearly, as the dry diameter decreases, the sensitivity to the model used increases. This can be explained as follows. Since water uptake is an exponential function of the water activity at equilibrium, and the Kelvin factor is larger for smaller particles, the calculated water content becomes more sensitive to the choice of model used at smaller dry diameters and higher $R H$. At $90 \% R H$ a $10 \mathrm{~nm}$ aerosol of this composition has a molality of around 2.8, the three different surface tension models covering a range of values from around 0.075 to 0.08 . At $61 \% R H$ the molality is around 6.7 , again resulting in a difference of around 0.005 . Figure $8 \mathrm{~b}$ provides the same analysis for an equimolar $\mathrm{H}_{2} \mathrm{SO}_{4}$ : $\left(\mathrm{NH}_{4}\right)_{2} \mathrm{SO}_{4}$ aerosol at $298.15 \mathrm{~K}$. At $61 \% \mathrm{RH}$ a $10 \mathrm{~nm}$ aerosol with this composition has a molality of around 8.3. At $90 \% R H$ the molality decreases to around 2.9. For these concentrations, the models differ by around 0.01 and 0.00275 , respectively. Although the standard deviation is relatively small, and growth factor deviation likely to be within the experimental uncertainty of the HTDMA, the increase at higher relative is likely 

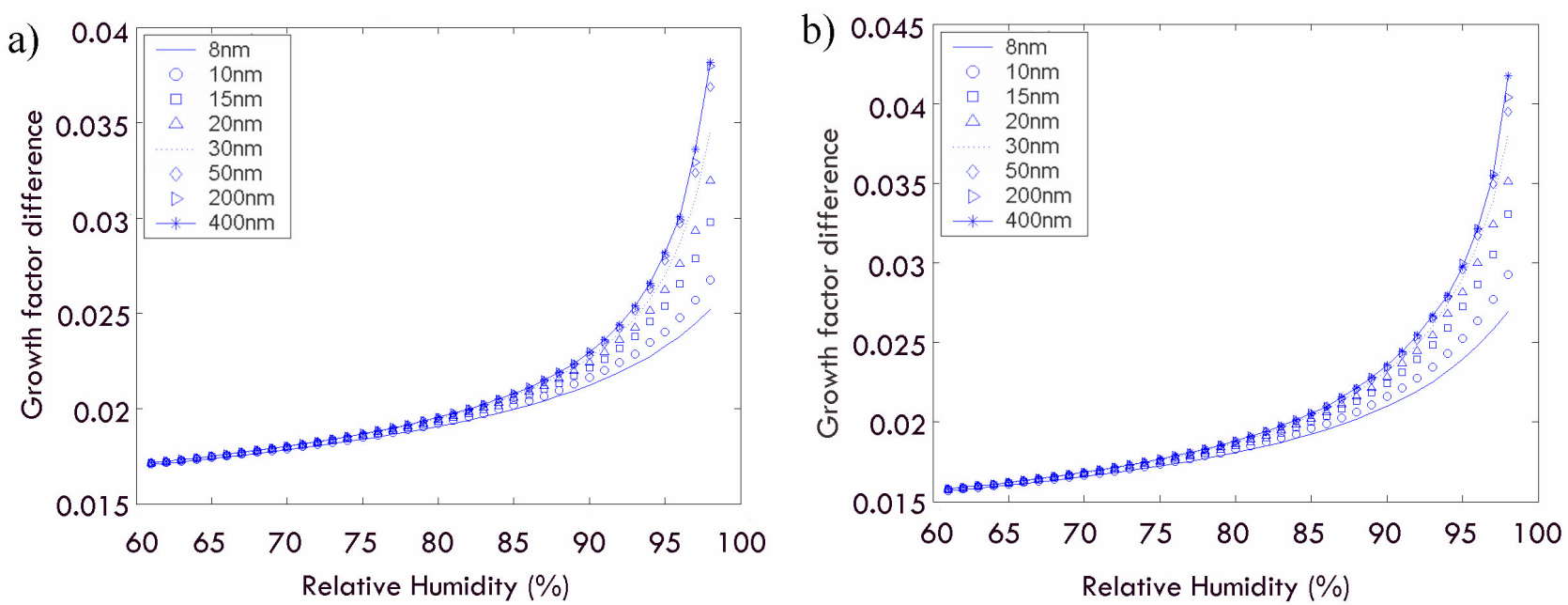

Fig. 9. (a) Growth factor difference for a $\left(\mathrm{NH}_{4}\right)_{2} \mathrm{SO}_{4}$ particle at $25^{\circ} \mathrm{C}$ and various dry diameters using two different density values. Values used were $1.769 \mathrm{~kg} / \mathrm{m}^{3}$ (Perry's Chemical handbook) and $1.7 \mathrm{~kg} / \mathrm{m}^{3}$ (Hameri et al., 2000). (b) Growth factor difference for a $\mathrm{NH}_{4} \mathrm{NO}_{3}$ particle at $25^{\circ} \mathrm{C}$ and various dry diameters using two different density values of $1.725 \mathrm{~kg} / \mathrm{m}^{3}$ (rhombic crystal) and $1.66 \mathrm{~kg} / \mathrm{m}^{3}$ (tetragonal crystal). Both values taken from Perry's Chemical handbook.

to have implications for any cloud activation studies. Indeed, whilst the surface tension of mixed electrolyte solutions does not differ greatly from that of pure water, the presence of organics can have significant effects thus making the ability to use various surface tension models important for any future applications. Various studies have highlighted the significant effect organics can have by lowering the surface tension (e.g. Mircea et al., 2002; Nenes et al., 2002). The sensitivity of hygroscopic growth, to choice of organic surface tension model, in sub-saturated humid regimes will be analysed in the accompanying paper to this report.

\subsection{Density}

\subsubsection{Aqueous density (mixing rules)}

The sensitivity of the growth factor calculation to the choice of density model, for the same binary systems, is shown in Fig. 8c, d. Here the mixing rule presented in Sect. 4.2 is used by using both mass and mole fraction of dry solute. As with the choice of surface tension model, the relative sensitivity between different dry sizes increases with decreasing dry diameter at larger $R H$. However, the deviation increases as the $R H$ decreases. As the solution becomes more concentrated, then the deviation between the two density mixing rules increases enough to overcompensate for the fact that the water content is less sensitive to the solution water activity. Thus, since the two mixing rules converge at low solution strengths, the deviation tends toward zero at higher relative humidity whilst maintaining a higher value for smaller dry diameters as discussed earlier. Again, the growth factor difference associated with the two separate mixing rules is likely to be within any experimental uncertainty associated with the HTDMA.

\subsubsection{Aqueous density (composition determination)}

In systems where there is one common cation, or anion, it is easy to define the solution composition with respect to the difference solutes associated with such ions. However, for mixtures with 2 or more different anion/cation pairs the system is ambiguously defined. Thus, one must chose an appropriate method for pairing the respective ions. This problem is faced in other predictive schemes such as the ZSR mixing rule, which will not be analysed here. There are a few options available that include elimination and equivalent concentration methods. The sensitivity of hygroscopicity predictions to such techniques are briefly analysed here. One method relies on the knowledge of the solute forms present (i.e. the user assumes the mixture to be composed of two solutes NX and MY with no variations). The second is a simple use of all possible permutations from the respective ions. Alternatively, one may use the mixing scheme of Reilly and Wood (1969) in which equivalent concentrations are defined using the relationship given below.

$N_{M X}=2 N_{m} N_{X} \frac{\left(Z_{m} Z_{X} /\left(V_{M(X)} V_{X(M)}\right)\right)^{1 / 2}}{\left(\sum_{c} N_{c} Z_{c}+\sum_{a} N_{a} Z_{a}\right)}$

where $N_{M}$ is the number of moles of components $M, Z_{M}$ the charge on component $M, V_{M(X)}$ the stoichiometric coefficient of component $M$ in the salt $N_{M X}$.

All were used with the mass fraction mixing rule of Tang (1997) to analyse the uncertainty. The systems 
studied were $\left(\mathrm{NH}_{4}\right)_{2} \mathrm{SO}_{4}: \mathrm{NaCl},\left(\mathrm{NH}_{4}\right)_{2} \mathrm{SO}_{4}: \mathrm{Na}_{2} \mathrm{SO}_{4}$ and $\left(\mathrm{NH}_{4}\right)_{2} \mathrm{SO}_{4}: \mathrm{NaNO}_{3}$.

Table 4 shows the standard deviation on GF for the 3 different combination rules at 3 different diameters and varying relative humidity. Clearly as the $R H$ decreases deviations increase. Similarly at higher $R H$ there is a greater distinction between sizes. Again, the range of deviations are not particularly large, though greater than those found for choice of density mixing rule. Indeed, deviations are more than an order of magnitude greater at $60 \% R \mathrm{H}$. For comparative purposes, such deviations are again likely to be within the experimental uncertainty of any measurements taken.

\subsubsection{Dry density}

There are also sensitivities to the value of the dry density used. Hameri et al. (2000) alluded to erroneous bulk density values used for small aerosols, in which structural complexities may cause significant deviations from the true value. They used a change in $\left(\mathrm{NH}_{4}\right)_{2} \mathrm{SO}_{4}$ density of $3.9 \%$ from 1.769 to $1.7 \mathrm{kgm}^{-3}$ in order to match up growth factor calculations for $8 \mathrm{~nm}$ dry diameter aerosols. Reported density values differ for different crystalline forms. For example, the density value for $\mathrm{NH}_{4} \mathrm{NO}_{3}$ given in Perry's Chemical handbook (Perry and Green, 1997) is reported for both rhombic and tetragonal forms (1.725 and $1.66 \mathrm{kgm}^{-3}$, respectively). Figure $9 \mathrm{a}$ and $\mathrm{b}$ highlights the sensitivity of the subsequent growth factor calculations to the value of dry density for both $\left(\mathrm{NH}_{4}\right)_{2} \mathrm{SO}_{4}$ and $\mathrm{NH}_{4} \mathrm{NO}_{3}$. For a $10 \mathrm{~nm} \mathrm{NH}_{4} \mathrm{NO}_{3}$ particle at $90 \% R H$ the change in GF is 0.0216 . For a $400 \mathrm{~nm}$ particle the change is 0.0235 . Using the bulk dry density for $\left(\mathrm{NH}_{4}\right)_{2} \mathrm{SO}_{4}$ and that reported by Hameri et al. (2000), the change in GF for a $10 \mathrm{~nm}$ diameter $\left(\mathrm{NH}_{4}\right)_{2} \mathrm{SO}_{4}$ particle at $90 \% R H$ is 0.0216 . Similarly for a $400 \mathrm{~nm}$ particle the difference is 0.023 . Interestingly, these changes in GF are larger than the deviations found for aqueous solution density. It is thus likely that the history of the aerosol studied in a HTDMA, specifically the nature of the drying process that will influence the final crystalline form, will create discrepancies upon comparisons with theoretical predictions. Mikhailov et al. (2004) considered such influences in detail. In their study the authors used the HTDMA to investigate the hygroscopic growth and microstructural rearrangement of aerosols composed of the protein $\mathrm{BSA}, \mathrm{NaCl}$ and $\mathrm{NH}_{4} \mathrm{NO}_{3}$. They found that depending on their origin and conditioning these particles can have complex and highly porous microstructures, which are influenced by electric charge effects and interactions with water vapour (Mikhailov et al., 2004).

\section{Conclusions}

A thermodynamic equilibrium model, built specifically to treat mixed inorganic/organic aerosols, which will be the focus of the accompanying paper to this report, has been pre-
Table 4. Growth factor standard deviations for 3 different systems using 3 different schemes for defining the aqueous composition (described in Sect. 7.3.2) from a knowledge of the ions present, for use in the simple density mixing rule defined in Sect. 4.2. Here the mass fraction of dry solute has been used in the simple formulation presented in Sect. 4.2. All calculations were made at $25^{\circ} \mathrm{C}$.

\begin{tabular}{|c|c|c|c|c|}
\hline \multirow[t]{2}{*}{$\overline{\mathrm{RH}}$} & \multirow{2}{*}{ Dry diameter $(\mathrm{nm})$} & \multicolumn{3}{|l|}{ System } \\
\hline & & 1 & 2 & 3 \\
\hline \multirow[t]{3}{*}{$60 \%$} & 8 & 0.01057 & 0.01080 & 0.00470 \\
\hline & 20 & 0.01061 & 0.01082 & 0.00469 \\
\hline & 400 & 0.01068 & 0.01087 & 0.00472 \\
\hline \multirow[t]{3}{*}{$70 \%$} & 8 & 0.00956 & 0.00981 & 0.00430 \\
\hline & 20 & 0.00960 & 0.00983 & 0.00429 \\
\hline & 400 & 0.00969 & 0.00991 & 0.00431 \\
\hline \multirow[t]{3}{*}{$80 \%$} & 8 & 0.00817 & 0.00847 & 0.00375 \\
\hline & 20 & 0.00817 & 0.00848 & 0.00371 \\
\hline & 400 & 0.00826 & 0.00859 & 0.00372 \\
\hline \multirow[t]{3}{*}{$90 \%$} & 8 & 0.00618 & 0.00658 & 0.00296 \\
\hline & 20 & 0.00596 & 0.00663 & 0.00279 \\
\hline & 400 & 0.0060 & 0.0064 & 0.0028 \\
\hline \multicolumn{5}{|c|}{ 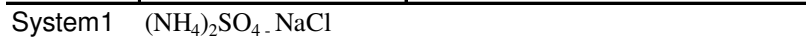 } \\
\hline em2 & \multicolumn{4}{|l|}{$\left(\mathrm{NH}_{4}\right)_{2} \mathrm{SO}_{4}-\mathrm{Na}_{2} \mathrm{SO}_{4}$} \\
\hline System3 & \multicolumn{4}{|l|}{$\left(\mathrm{NH}_{4}\right)_{2} \mathrm{SO}_{4}-\mathrm{NaNO}_{3}$} \\
\hline
\end{tabular}

sented which can also treat the Kelvin effect. The framework which one develops to treat the hygroscopic properties of aerosols can determine both the accuracy and the range of applicability of the model. Indeed, given that errors associated with the organic fraction are likely to be substantial, it is imperative to create a robust inorganic framework on which to include organics. A direct minimisation of the Gibbs free energy has been used here where all of the components are freely variable within set charge and mass constraints. In this way, the model does not rely solely upon the use of mixing rules for calculating the water content but can employ potentially more accurate semi empirical thermodynamic models. Here the state of the art activity model of Clegg and Pitzer (1992); Clegg et al. (1992) is used following GFEMN (Ansari and Pandis, 1999) and AIM (Clegg et al., 1998a, b), allowing the model to deal with higher concentrations, often supersaturated, than would be possible using Pitzer's molality based model. Similar to GFEMN, adjusted energies of formation are used to predict multistage behaviour. This may introduce some inconsistencies with the activity model employed. However, as found by Ansari and Pandis (1999) the use of such parameters allows the model to accurately predict the deliquescence behaviour of multi-component aerosols.

Unlike the majority of equilibrium models available, the model presented here can treat the influence of curvature on aerosol composition. Circumventing the complexities of treating the curvature term explicitly in the energy summation, the model relies upon the use of the Kohler equation to describe the equilibration of water between the liquid and 
gaseous phase. In this way, the model is housed within an iterative loop, using a guaranteed convergence scheme to attain the solution pertaining to the new definition of equilibrium. Unlike other diameter dependent thermodynamic models, this enables one to use any model for the surface tension and density of solution without requiring complex derivatives. Such features will be useful when treating mixed inorganic/organic systems. Comparisons with another diameter dependent thermodynamic model (Ming and Russell, 2001) showed that this model can reproduce diameter dependent phenomena including the onset of deliquescence. Comparisons with a diameter dependent growth factor parameterisation shows that as the number of the components increases and the solution becomes more concentrated, then the advantages of an explicit thermodynamic treatment become apparent. Indeed, the deviations are likely to be outside experimental uncertainty for such conditions. In addition, where available, the treatment of solid precipitation is a great advantage for field/laboratory comparisons.

The model is subject to various sensitivities. For the inorganic systems studied here, the sensitivity to choice of surface tension model used decreases for larger aerosol. A similar trend for the choice of density mixing rule is found, although the difference between the density models at lower $R H$ is large enough to offset the decreased sensitivity of water content to calculated water activity in these regions. Interestingly, larger sensitivities are found for the value of dry density used. It is thus likely that the history of the aerosol studied in a HTDMA, specifically the nature of the drying process that will influence the final crystalline form, will create systematic uncertainties upon comparisons with theoretical predictions. However, the magnitudes of all of the above sensitivities are potentially less than those introduced when using a semi ideal ZSR growth factor analogue for certain conditions.

Acknowledgements. This work was supported by the UK Natural Environment Research Council (NERC) studentship NER/S/A/2001/06423.

Edited by: U. Pöschl

\section{References}

Ansari, A. S. and Pandis, S. N.: Prediction of multicomponent inorganic atmospheric aerosol behavior, Atmos. Environ., 33 (5), 745-757, 1999.

Bassett, M. and Seinfeld, J. H.: Atmospheric Equilibrium-Model of Sulfate and Nitrate Aerosols, Atmos. Environ., 17 (11), 22372252, 1983.

Bassett, M. E. and Seinfeld, J. H.: Atmospheric Equilibrium-Model of Sulfate and Nitrate Aerosols, 2. Particle-Size Analysis, Atmos. Environ., 18 (6), 1163-1170, 1984.

Bilde, M. and Svenningsson, B.: CCN activation of slightly soluble organics: the importance of small amounts of inorganic salt and particle phase, Tellus B, 56 (2), 128-134, 2004.
Binkowski, F. S. and Shankar, U.: The Regional Particulate Matter Model, 1. Model description and preliminary results, J. Geophys. Res., 100(D12), 26 191-26209, 1995.

Brechtel, F. J. and Kreidenweis, S. M.: Predicting particle critical supersaturation from hygroscopic growth measurements in the humidified TDMA, part I: Theory and sensitivity studies, J. Atmos. Sci., 57 (12), 1854-1871, 2000a.

Brechtel, F. J. and Kreidenweis, S. M.: Predicting particle critical supersaturation from hygroscopic growth measurements in the humidified TDMA, Part II: Laboratory and ambient studies, J. Atmos. Sci., 57 (12), 1872-1887, 2000b.

Chan, C. K., Flagan, R. C., and Seinfeld, J. H.: Water Activities of NH4NO3/(NH4)2SO4 Solutions, Atmos. Environ., 26 (9), 1661-1673, 1992.

Chan, C. K., Ha, Z. Y., and Choi, M. Y.: Study of water activities of aerosols of mixtures of sodium and magnesium salts, Atmos. Environ., 34 (28), 4795-4803, 2000.

Chen, J. P.: Theory of Deliquescence and Modified Kohler Curves, J. Atmos. Sci., 51 (23), 3505-3516, 1994.

Chylek, P. and Wong, J. G. D.: Erroneous use of the modified Kohler equation in cloud and aerosol physics applications, J. Atmos. Sci., 55 (8), 1473-1477, 1998.

Clegg, S. L. and Brimblecombe, P.: Equilibrium Partial Pressures of Strong Acids over Concentrated Saline Solutions, 2. Hcl, Atmos. Environ., 22 (1), 117-129, 1988.

Clegg, S. L., Brimblecombe, P., and Wexler, A. S.: Thermodynamic model of the system H+-NH4+-Na+-SO42-NB3-ClH2O at 298.15 K, J. Phys. Chem. A, 102 (12), 2155-2171, 1998a.

Clegg, S. L., Brimblecombe, P., and Wexler, A. S.: Thermodynamic model of the system H+-NH4+-SO42-NO3-H2O at tropospheric temperatures, J. Phys. Chem. A, 102 (12), 2137-2154, 1998b.

Clegg, S. L. and Pitzer, K. S.: Thermodynamics of Multicomponent, Miscible, Ionic-Solutions - Generalized Equations for Symmetrical Electrolytes, J. Phys. Chem., 96 (8), 3513-3520, 1992.

Clegg, S. L., Pitzer, K. S., and Brimblecombe, P.: Thermodynamics of Multicomponent, Miscible, Ionic-Solutions, 2. Mixtures Including Unsymmetrical Electrolytes, J. Phys. Chem., 96 (23), 9470-9479, 1992.

Clegg, S. L., Seinfeld, J. H., and Edney, E. O.: Thermodynamic modelling of aqueous aerosols containing electrolytes and dissolved organic compounds. II. An extended Zdanovskii-StokesRobinson approach, J. Aerosol. Sci., 34 (6), 667-690, 2003.

Cohen, M. D., Flagan, R. C., and Seinfeld, J. H.: Studies of Concentrated Electrolyte-Solutions Using the Electrodynamic Balance, 1. Water Activities for Single-Electrolyte Solutions, J. Phys. Chem., 91 (17), 4563-4574, 1987a.

Cohen, M. D., Flagan, R. C., and Seinfeld, J. H.: Studies of Concentrated Electrolyte-Solutions Using the Electrodynamic Balance, 2. Water Activities for Mixed-Electrolyte Solutions, J. Phys. Chem., 91 (17), 4575-4582, 1987b.

Corrigan, C. E. and Novakov, T.: Cloud condensation nucleus activity of organic compounds: a laboratory study, Atmos. Environ., 33 (17), 2661-2668, 1999.

Crocker, L. S., Varsolona, R. J., and McCauley, J. A.: Two methods for the measurement of the dissociation pressure of a crystalline hydrate, J. Pharmaceut. Biomed., 15 (11), 1661-1665, 1997. 
Cruz, C. N. and Pandis, S. N.: Deliquescence and hygroscopic growth of mixed inorganic-organic atmospheric aerosol, Environ. Sci. Technol., 34 (20), 4313-4319, 2000.

Denbigh, K.G.: The Principles of Chemical Equilibrium: With Applications in Chemistry and Chemical Engineering, Cambridge University Press, 1981.

Finlayson-Pitts, B. J. and Hemminger, J. C.: Physical chemistry of airborne sea salt particles and their components, J. Phys. Chem. A, 104 (49), 11 463-11477, 2000.

Fisher, L. R. and Israelachvili, J. N.: Direct ExperimentalVerification of the Kelvin Equation for Capillary Condensation, Nature, 277 (5697), 548-549, 1979.

Ghosal, S. and Hemminger, J. C.: Effect of water on the HNO3 pressure dependence of the reaction between gas-phase HNO3 and $\mathrm{NaCl}$ surfaces, J. Phys. Chem. A, 103 (25), 4777-4781, 1999.

Girshick, S. L. and Chiu, C. P.: Kinetic Nucleation Theory - a New Expression for the Rate of Homogeneous Nucleation from an Ideal Supersaturated Vapor, J. Chem. Phys., 93 (2), 1273-1277, 1990.

Ha, Z. Y., Choy, L., and Chan, C. K.: Study of water activities of supersaturated aerosols of sodium and ammonium salts, J. Geophys. Res., 105(D9), 11 699-11 709, 2000.

Hameri, K., Charlson, R., and Hansson, H. C.: Hygroscopic properties of mixed ammonium sulfate and carboxylic acids particles, Aiche J., 48 (6), 1309-1316, 2002.

Hameri, K., Vakeva, M., Hansson, H. C., and Laaksonen, A.: Hygroscopic growth of ultrafine ammonium sulphate aerosol measured using an ultrafine tandem differential mobility analyzer, J. Geophys. Res., 105(D17), 22 231-22 242, 2000.

Harrison, R. M. and Sturges, W. T.: Physicochemical Speciation and Transformation Reactions of Particulate Atmospheric Nitrogen and Sulfur-Compounds, Atmos. Environ., 18 (9), 18291833, 1984.

Hu, Y. F. and Lee, H.: Prediction of the surface tension of mixed electrolyte solutions based on the equation of Patwardhan and Kumar and the fundamental Butler equations, J. Colloid. Interf. Sci., 269 (2), 442-448, 2004.

Jacobson, M. Z.: Fundamentals of Atmospheric Modelling, Cambridge University Press, 1999a.

Jacobson, M. Z.: Studying the effects of calcium and magnesium on size-distributed nitrate and ammonium with EQUISOLV II, Atmos. Environ., 33 (20), 3635-3649, 1999b.

Jacobson, M. Z., Tabazadeh, A., and Turco, R. P.: Simulating equilibrium within aerosols and nonequilibrium between gases and aerosols, J. Geophys. Res., 101(D4), 9079-9091, 1996.

Kim, Y. P. and Seinfeld, J. H.: Atmospheric Gas-Aerosol Equilibrium, 3. Thermodynamics of Crustal Elements $\mathrm{Ca} 2+, \mathrm{K}+$, and Mg2+, Aerosol. Sci. Technol., 22 (1), 93-110, 1995.

Kim, Y. P., Seinfeld, J. H., and Saxena, P.: Atmospheric Gas Aerosol Equilibrium, 1. Thermodynamic Model, Aerosol. Sci. Technol., 19 (2), 157-181, 1993a.

Kim, Y. P., Seinfeld, J. H., and Saxena, P.: Atmospheric GasAerosol Equilibrium, 2. Analysis of Common Approximations and Activity-Coefficient Calculation Methods, Aerosol. Sci. Technol., 19 (2), 182-198, 1993b.

Kiss, G. and Hansson, H.-C.: Application of osmolality for the determination of water activity and the modelling of cloud formation, Atmos. Chem. Phys. Discuss., 4, 7667-7689, 2004,
SRef-ID: 1680-7375/acpd/2004-4-7667.

Kreidenweis, S. M., Koehler, K., DeMott, P., Prenni, A. J., Carrico, C., and Ervens, B.: Water activity and activation diameters from hgroscopicity data Part 1: Theory and application to inorganic salts, Atmos. Chem. Phys. Discuss., 5, 287-323, 2005,

SRef-ID: 1680-7375/acpd/2005-5-287.

Laaksonen, A., Korhonen, P., Kulmala, M., and Charlson, R. J.: Modification of the Kohler equation to include soluble trace gases and slightly soluble substances, J. Atmos. Sci., 55 (5), 853862, 1998.

Li, Z. B., Li, Y. G., and Lu, J. F.: Surface tension model for concentrated electrolyte aqueous solutions by the Pitzer equation, Ind. Eng. Chem. Res., 38 (3), 1133-1139, 1999.

Li, Z. B. and Lu, B. C. Y.: Surface tension of aqueous electrolyte solutions at high concentrations - representation and prediction, Chem. Eng. Sci., 56 (8), 2879-2888, 2001.

Malm, W. C. and Kreidenweis, S. M.: The effects of models of aerosol hygroscopicity on the apportionment of extinction, Atmos. Environ., 31 (13), 1965-1976, 1997.

Martin, S. T., Hung, H. M., Park, R. J., Jacob, D. J., Spurr, R. J. D., Chance, K. V., and Chin, M.: Effects of the physical state of tropospheric ammonium-sulfate-nitrate particles on global aerosol direct radiative forcing, Atmos. Chem. Phys., 4, 183-214, 2004, SRef-ID: 1680-7324/acp/2004-4-183.

Meng, Z. Y., Seinfeld, J. H., Saxena, P., and Kim, Y. P.: Atmospheric Gas-Aerosol Equilibrium, 4. Thermodynamics of Carbonates, Aerosol. Sci. Tech., 23 (2), 131-154, 1995.

Metzger, S., Dentener, F., Krol, M., Jeuken, A., and Lelieveld, J.: Gas/aerosol partitioning - 2. Global modeling results, J. Geophys. Res., 107(D16), art. no. 4313, 2002a.

Metzger, S., Dentener, F., Pandis, S., and Lelieveld, J.: Gas/aerosol partitioning: 1. A computationally efficient model, J. Geophys. Res., 107(D16), art. no. 4312, 2002b.

Mikhailov, E., Vlasenko, S., Niessner, R., and Pöschl, U.: Interaction of aerosol particles composed of protein and salts with water vapor: hygroscopic growth and microstructural rearrangement, Atmos. Chem. Phys., 4, 323-350, 2004,

SRef-ID: 1680-7324/acp/2004-4-323.

Ming, Y. and Russell, L. M.: Predicted hygroscopic growth of sea salt aerosol, J. Geophys. Res., 106(D22), 28 259-28 274, 2001.

Ming, Y. and Russell, L. M.: Thermodynamic equilibrium of organic-electrolyte mixtures in aerosol particles, Aiche J., 48 (6), 1331-1348, 2002.

Mirabel, P., Reiss, H., and Bowles, R. K.: A theory for the deliquescence of small particles, J. Chem. Phys., 113 (18), 8200-8205, 2000.

Mircea, M., Facchini, M. C., Decesari, S., Fuzzi, S., and Charlson, R. J.: The influence of the organic aerosol component on CCN supersaturation spectra for different aerosol types, Tellus B, 54 (1), 74-81, 2002.

Nenes, A., Charlson, R. J., Facchini, M. C., Kulmala, M., Laaksonen, A., and Seinfeld, J. H.: Can chemical effects on cloud droplet number rival the first indirect effect?, Geophys. Res. Lett., 29 (17), art. no. 1848, 2002.

Nenes, A., Pandis, S. N., and Pilinis, C.: ISORROPIA: A new thermodynamic equilibrium model for multiphase multicomponent inorganic aerosols, Aquat. Geochem., 4 (1), 123-152, 1998.

Nenes, A., Pandis, S. N., and Pilinis, C.: Continued development and testing of a new thermodynamic aerosol module for urban 
and regional air quality models, Atmos. Environ., 33 (10), 15531560, 1999.

Perry, R. H. and Green, D. W.: Perry's Chemical Engineers Handbook (7th edition), McGraw-Hill, 1997.

Pilinis, C.: Modelling atmospheric aerosols using thermodynamics arguments - a review, Global Nest: The international journal, 1 (1), 5-13, 1999.

Pilinis, C., Pandis, S. N., and Seinfeld, J. H.: Sensitivity of Direct Climate Forcing by Atmospheric Aerosols to Aerosol-Size and Composition, J. Geophys. Res., 100(D9), 18 739-18 754, 1995.

Pilinis, C. and Seinfeld, J. H.: Continued Development of a General Equilibrium-Model for Inorganic Multicomponent Atmospheric Aerosols, Atmos. Environ., 21 (11), 2453-2466, 1987.

Pilinis, C., Seinfeld, J. H., and Grosjean, D.: Water-Content of Atmospheric Aerosols, Atmos. Environ., 23 (7), 1601-1606, 1989.

Pitchford, M. L. and Mcmurry, P. H.: Relationship between Measured Water-Vapor Growth and Chemistry of Atmospheric Aerosol for Grand-Canyon, Arizona, in Winter 1990, Atmos. Environ., 28 (5), 827-839, 1994.

Pitzer, K. S.: Thermodynamics of Electrolytes, 1. Theoretical Basis and General Equations, J. Phys. Chem., 77 (2), 268-277, 1973.

Pitzer, K. S.: Thermodynamics of Electrolytes, 5. Effects of HigherOrder Electrostatic Terms, J. Solution Chem., 4 (3), 249-265, 1975.

Pitzer, K. S. and Mayorga, G.: Thermodynamics of Electrolytes, 2. Activity and Osmotic Coefficients for Strong Electrolytes with One or Both Ions Univalent, J. Phys. Chem., 77 (19), 2300-2308, 1973.

Pitzer, K. S. and Silvester, L. F.: Thermodynamics of Electrolytes, 6. Weak Electrolytes Including H3po4, J. Solution Chem., 5 (4), 269-278, 1976.

Press, W. H., Teukolsky, S. A., Vetterling, W. T., and Flannery, B. P.: Numerical recipes in Fortran 77, The Art of Scientific Computing, Cambridge University Press, 1992.

Pruppacher, H. R. and Klett, J. D.: Microphysics of clouds and precipitation, Kluwer, Dordrecht, 1997.

Reilly, P. J. and Wood, R. H.: Prediction of Properties of Mixed Electrolytes from Measurements on Common Ion Mixtures, J. Phys. Chem., 73 (12), 4292-4297, 1969.

Reiss, H. and Koper, G. J. M.: The Kelvin Relation - Stability, Fluctuation, and Factors Involved in Measurement, J. Phys. Chem., 99 (19), 7837-7844, 1995.

Russell, L. M. and Ming, Y.: Deliquescence of small particles, J. Chem. Phys., 116 (1), 311-321, 2002.

Saxena, P., Hudischewskyj, A. B., Seigneur, C., and Seinfeld, J. H.: A Comparative-Study of Equilibrium Approaches to the Chemical Characterization of Secondary Aerosols, Atmos. Environ., 20 (7), 1471-1483, 1986.

Seinfeld, J. H. and Pandis, S. N.: Atmospheric Chemistry and Physics, Wiley-Interscience publication, 1998.

Shulman, M. L., Jacobson, M. C., Charlson, R. J., Synovec, R. E., and Young, T. E.: Dissolution behavior and surface tension effects of organic compounds in nucleating cloud droplets (vol. 23, p. 277, 1996), Geophys. Res. Lett., 23 (5), 603-603, 1996.

Stelson, A. W. and Seinfeld, J. H.: Relative-Humidity and Temperature-Dependence of the Ammonium-Nitrate Dissociation-Constant, Atmos. Environ., 16 (5), 983-992, 1982.
Stokes, R. H. and Robinson, R. A.: Interactions in Aqueous Nonelectrolyte Solutions, I. Solute-Solvent Equilibria, J. Phys. Chem., 70 (7), 2126-2131, 1966.

Suarez, J. T., Torres-Marchal, C., and Rasmussen, P.: Prediction of surface tension of nonelectrolyte solutions, Chem. Eng. Sci., 44 (3), 782-786, 1989.

Swietlicki, E., Zhou, J. C., Berg, O. H., Martinsson, B. G., Frank, G., Cederfelt, S. I., Dusek, U., Berner, A., Birmili, W., Wiedensohler, A., Yuskiewicz, B., and Bower, K. N.: A closure study of sub-micrometer aerosol particle hygroscopic behaviour, Atmos. Res., 50 (3-4), 205-240, 1999.

Tang, I. N.: Thermodynamic and optical properties of mixed-salt aerosols of atmospheric importance, J. Geophys. Res., 102(D2), 1883-1893, 1997.

Tang, I. N. and Munkelwitz, H. R.: Nitric-Acid and Water Activities of Mixed Sulfate and Nitrate Aerosols, Abstr. Pap. Am. Chem. S., 182 (AUG), 183-Phys, 1981.

Tang, I. N. and Munkelwitz, H. R.: Water Activities, Densities, and Refractive-Indexes of Aqueous Sulfates and Sodium-Nitrate Droplets of Atmospheric Importance, J. Geophys. Res., 99(D9), 18 801-18 808, 1994.

Tang, I. N., Munkelwitz, H. R., and Wang, N.: Water Activity Measurements with Single Suspended Droplets: The NaCl-H2O and KCl-H2O Systems, J. Colloid Interf. Sci., 114, 409-415, 1986.

Topping, D. O., McFiggans, G. B., and Coe, H.: A curved multicomponent aerosol hygroscopicity model framework: 2 Including organics, Atmos. Chem. Phys. Discuss., 4, 8677-8726, 2004, SRef-ID: 1680-7375/acpd/2004-4-8677.

Weis, D. D. and Ewing, G. E.: Water content and morphology of sodium chloride aerosol particles, J. Geophys. Res., 104(D17), $21275-21285,1999$.

Wexler, A. S. and Clegg, S. L.: Atmospheric aerosol models for systems including the ions $\mathrm{H}+, \mathrm{NH} 4+, \mathrm{Na}+, \mathrm{SO} 42-, \mathrm{NO} 3-, \mathrm{Cl}-$, Br-, and H2O, J. Geophys. Res., 107(D14), art. no. 4207, 2002.

Wexler, A. S. and Seinfeld, J. H.: The Distribution of AmmoniumSalts among a Size and Composition Dispersed Aerosol, Atmos. Environ., 24 (5), 1231-1246, 1990.

Wexler, A. S. and Seinfeld, J. H.: 2nd-Generation Inorganic Aerosol Model, Atmos Enviro, 25 (12), 2731-2748, 1991.

Wilemski, G.: Composition of the Critical Nucleus in Multicomponent Vapor Nucleation, J. Chem. Phys., 80 (3), 1370-1372, 1984.

Wilemski, G.: The Kelvin Equation and Self-Consistent Nucleation Theory, J. Chem. Phys., 103 (3), 1119-1126, 1995.

Zhang, Y., Seigneur, C., Seinfeld, J. H., Jacobson, M., Clegg, S. L., and Binkowski, F. S.: A comparative review of inorganic aerosol thermodynamic equilibrium modules: similarities, differences, and their likely causes, Atmos. Environ., 34 (1), 117-137, 2000.

Zhou, J. L., Tits, A. L., and Lawrence, C. T.: Users Guide for FFSQP Version 3.7:A FORTRAN code for solving optimisation problems, possibly minimax, with general inequality constraints and linear equality constraints, generating feasible iterates, University of Maryland, technical Report SRC-TR-92-107r5, College Park, MD 20742, 1997. 